\title{
Article \\ Characterization of Root System Architecture Traits in Diverse Soybean Genotypes Using a Semi-Hydroponic System
}

\author{
Shuo Liu ${ }^{1}$, Naheeda Begum ${ }^{2}$, Tingting An ${ }^{1}$, Tuanjie Zhao ${ }^{2} \mathbb{D}$, Bingcheng Xu ${ }^{1} \mathbb{D}$, Suiqi Zhang ${ }^{1}$, Xiping Deng ${ }^{1}$, \\ Hon-Ming Lam ${ }^{3}\left(\mathbb{D}\right.$, Henry T. Nguyen ${ }^{4}\left(\mathbb{D}\right.$, Kadambot H. M. Siddique ${ }^{5}$ and Yinglong Chen ${ }^{1,5, *(\mathbb{D})}$
}

1 College of Natural Resources and Environment, and State Key Laboratory of Soil Erosion and Dryland Farming on the Loess Plateau, Northwest A\&F University, Xi'an 712100, China; liushuo@nwafu.edu.cn (S.L.); tingtingan2018@nwafu.edu.cn (T.A.); bcxu@ms.iswc.ac.cn (B.X.); sqzhang@ms.iswc.ac.cn (S.Z.); dengxp@ms.iswc.ac.cn (X.D.)

2 National Center for Soybean Improvement, Key Laboratory of Biology and Genetics and Breeding for Soybean, Ministry of Agriculture, State Key Laboratory for Crop Genetics and Germplasm Enhancement, Nanjing Agricultural University, Nanjing 210095, China; T2020106@njau.edu.cn (N.B.); tjzhao@njau.edu.cn (T.Z.)

3 Center for Soybean Research of the State Key Laboratory of Agrobiotechnology, School of Life Sciences, The Chinese University of Hong Kong, Shatin, Hong Kong, China; honming@cuhk.edu.hk

4 Division of Plant Sciences, University of Missouri, Columbia, MO 65211, USA; NguyenHenry@missouri.edu

5 The UWA Institute of Agriculture, School of Agriculture and Environment, The University of Western Australia, Perth 6009, Australia; kadambot.siddique@uwa.edu.au

Citation: Liu, S.; Begum, N.; An, T.; Zhao, T.; Xu, B.; Zhang, S.; Deng, X.; Lam, H.-M.; Nguyen, H.T.; Siddique, K.H.M.; et al. Characterization of Root System Architecture Traits in Diverse Soybean Genotypes Using a Semi-Hydroponic System. Plants 2021, 10, 2781. https://doi.org/ $10.3390 /$ plants 10122781

Academic Editors: Viktor Demko, Ján Jásik, Alexander Lux and Marek Vaculík

Received: 1 November 2021 Accepted: 10 December 2021 Published: 16 December 2021

Publisher's Note: MDPI stays neutral with regard to jurisdictional claims in published maps and institutional affiliations.

Copyright: (c) 2021 by the authors. Licensee MDPI, Basel, Switzerland. This article is an open access article distributed under the terms and conditions of the Creative Commons Attribution (CC BY) license (https:/ / creativecommons.org/licenses/by/ $4.0 /)$.
* Correspondence: yinglong.chen@uwa.edu.au; Tel.: +61-8-6488-2501

\begin{abstract}
Phenotypic variation and correlations among root traits form the basis for selecting and breeding soybean varieties with efficient access to water and nutrients and better adaptation to abiotic stresses. Therefore, it is important to develop a simple and consistent system to study root traits in soybean. In this study, we adopted the semi-hydroponic system to investigate the variability in root morphological traits of 171 soybean genotypes popularized in the Yangtze and Huaihe River regions, eastern China. Highly diverse phenotypes were observed: shoot height $(18.7-86.7 \mathrm{~cm}$ per plant with a median of $52.3 \mathrm{~cm})$; total root length $(208-1663 \mathrm{~cm}$ per plant with a median of $885 \mathrm{~cm})$; and root mass (dry weight) (19.4-251 mg per plant with a median of $124 \mathrm{mg}$ ). Both total root length and root mass exhibited significant positive correlation with shoot mass ( $p \leq 0.05)$, indicating their relationship with plant growth and adaptation strategies. The nine selected traits contributed to one of the two principal components (eigenvalues $>1$ ), accounting for $78.9 \%$ of the total genotypic variation. Agglomerative hierarchical clustering analysis separated the 171 genotypes into five major groups based on these root traits. Three selected genotypes with contrasting root systems were validated in soil-filled rhizoboxes (1.5 $\mathrm{m}$ deep) until maturity. Consistent ranking of the genotypes in some important root traits at various growth stages between the two experiments indicates the reliability of the semi-hydroponic system in phenotyping root trait variability at the early growth stage in soybean germplasms.
\end{abstract}

Keywords: soybean; root phenomics; root system architecture; root distribution

\section{Introduction}

Soybean (Glycine max L. Merr.) is an important leguminous crop that is used for human food, animal feed, biofuel production, and many other products due to its high protein and edible oil content [1]. Soybean is native to China and is the fourth largest crop after rice (Oryza sativa L.), wheat (Triticum aestivum L.), and corn (Zea mays L.) of the world. It is grown on an estimated $6 \%$ of the world's arable land [1,2]. In China, the region between the Yangtze and Huaihe Rivers is among the major soybean-producing area [2]. Studies have investigated crop growth and yield constraints, and there is increasing interest in soybean varieties with suitable root systems to effectively use resources and improve 
yield [3-5]. Plant root systems play an essential role in water and nutrient acquisition, and they can perceive and respond to various edaphic stresses before other plant organs, such as drought, waterlogging, salinity, and soil infertility [6-13].

Root system architecture (RSA) is plastic and dynamic, allowing plants to respond to their environments to enhance nutrients and water acquisition [14,15]. Alterations to root growth and RSA are critical adaptive strategies of crops to cope with drought, soil infertility, and other edaphic stresses [16]. Therefore, it is important to screen and breed crop cultivars with better RSA, which can adapt to edaphic stresses and have improved nutrient and water efficiency $[17,18]$. The identification of RSA conferring efficiencies in resource acquisition and adaptation to edaphic stresses has increased in research and breeding programs $[19,20]$. Some studies have evaluated the phenology and morphological characters of many soybean genetic resources [6,21]. Research on soybean in the Yangtze and Huaihe River region of eastern China has mainly focused on seed traits, pod traits, shoot traits, and flowering time [22-28]. Studies on soybean root traits are limited due to the lack of reliable and efficient non-destructive methods $[29,30]$.

A semi-hydroponic phenotyping system [31] has been used to characterize root traits in large numbers of germplasm in various crop species, including narrow-leafed lupin (Lupinus angustifolius L.) [32-34], chickpea (Cicer arietinum L.) [35], maize (Zea mays L.) [36], wheat (Triticum aestivum L.) [37,38], and barley (Hordeum vulgare L.) [39], but not in soybean. In this study, we characterized phenotypic variability in root morphology at the seedling stage of the 171 diverse genotypes with good agronomic traits mainly developed for the Yangtze and Huaihe Rivers in eastern China. The root growth of three selected soybean genotypes was mapped in a follow-up validation study in soil-filled deep rhizoboxes.

\section{Results}

2.1. Adopting a Semi-Hydroponic System to Characterize 171 Soybean Accessions

\subsubsection{Global Traits}

Global traits include nine root traits and four shoot traits (Table 2). The nine root traits reflected the pattern of root distribution and development. Among them, maximal root depth $(\mathrm{CV}=0.16)$, root width $(\mathrm{CV}=0.18)$, root angle $(\mathrm{CV}=0.26)$, total root length $(\mathrm{CV}=0.37)$, average root diameter $(\mathrm{CV}=0.07)$, root mass $(\mathrm{CV}=0.44)$, and root-shoot mass ratio $(\mathrm{CV}=0.27)$ significantly different among genotypes (all $p<0.01)$, while the specific root length $(\mathrm{CV}=0.49)$ and root tissue density $(\mathrm{CV}=0.28)$ did not significantly differ among genotypes (Table 1$)$. Four shoot-related traits, leaf number $(\mathrm{CV}=0.14)$, hypocotyl length $(\mathrm{CV}=0.27)$, shoot height $(\mathrm{CV}=0.22)$, and shoot mass $(\mathrm{CV}=0.33)$ significantly differed among genotypes (all $p<0.01$; Table 1 ).

Root mass ranged from 19.4 (genotype \#071) to 251 (\#055) mg per plant with a median value of $124 \mathrm{mg}$ (Table 1). About $63 \%$ of the 171 genotypes had root mass values $>110 \mathrm{mg}$ per plant. Total root length (RL) ranged from 208 (\#071) to 1663 (\#055) cm per plant with a median value of $885 \mathrm{~cm}$ (Table 1, Figure 2). Among the 171 genotypes, four genotypes had $\mathrm{RL}<300 \mathrm{~cm}$ per plant, 157 genotypes had RL values from 300 to $1300 \mathrm{~cm}$ per plant, and ten genotypes had RL $>1300 \mathrm{~cm}$ (Figure 2). Based on the RL value of each genotype compared to the median value ( $885 \mathrm{~cm}$ per plant) of $\mathrm{RL} \pm$ two standard error, the 171 soybean genotypes were divided into three root sizes; 58 genotypes were considered as having a small root system ( $\mathrm{RL}<850 \mathrm{~cm}$ per plant), 68 genotypes were considered as having a large root system (RL $>913 \mathrm{~cm}$ per plant), and 45 genotypes were considered as having a medium root system $(850 \leq \mathrm{RL} \leq 913 \mathrm{~cm}$ per plant) (Table S1). The root mass, root length distribution of fine roots (diameter class $<0.5 \mathrm{~mm}$ ), and coarse roots (diameter class $\geq 0.5 \mathrm{~mm}$ ) followed similar trends to RL for the three root size classes (Figure 3). 
Table 1. Descriptive statistics of 18 measured traits (13 global and five local traits) in 171 soybean genotypes grown in a semi-hydroponic phenotyping platform assessed 39 days after sowing.

\begin{tabular}{|c|c|c|c|c|c|c|c|}
\hline Trait & Minimum & Maximum & Median & Mean & Std. Dev. & $\mathrm{CV}$ & $p$ Value \\
\hline MRD & 28.8 & 65.0 & 47.5 & 46.6 & 7.37 & 0.16 & $<0.001$ \\
\hline RW & 9.57 & 20.5 & 14.7 & 14.9 & 2.70 & 0.18 & $<0.001$ \\
\hline RA & 63.0 & 160 & 109 & 109 & 28.0 & 0.26 & $<0.001$ \\
\hline RL & 208 & 1663 & 885 & 898 & 331 & 0.37 & $<0.001$ \\
\hline RD & 0.20 & 0.47 & 0.42 & 0.42 & 0.03 & 0.07 & $<0.001$ \\
\hline $\mathrm{RM}$ & 19.4 & 251 & 124 & 127 & 55.8 & 0.44 & $<0.001$ \\
\hline SRL & 5.27 & 25.6 & 7.33 & 7.72 & 3.81 & 0.49 & 0.64 \\
\hline RTD & 98.0 & 219 & 141 & 143 & 40.2 & 0.28 & 0.91 \\
\hline RSM & 0.11 & 0.32 & 0.19 & 0.19 & 0.05 & 0.27 & $<0.001$ \\
\hline LN & 3.00 & 6.00 & 5.00 & 4.81 & 0.67 & 0.14 & $<0.001$ \\
\hline HL & 2.20 & 9.10 & 4.50 & 4.55 & 1.24 & 0.27 & $<0.001$ \\
\hline $\mathrm{SH}$ & 18.7 & 86.7 & 52.3 & 51.0 & 11.3 & 0.22 & $<0.001$ \\
\hline $\mathrm{SM}$ & 164 & 1150 & 663 & 652 & 213 & 0.33 & $<0.001$ \\
\hline RL-upper & 152 & 1146 & 664 & 662 & 226 & 0.34 & $<0.001$ \\
\hline RL-lower & 11.5 & 654 & 223 & 236 & 136 & 0.58 & $<0.001$ \\
\hline RL-fine & 134 & 908 & 448 & 450 & 208 & 0.46 & $<0.001$ \\
\hline RL-coarse & 175 & 1551 & 849 & 845 & 309 & 0.37 & $<0.001$ \\
\hline RLR-upper/lower & 1.18 & 16.5 & 3.27 & 3.59 & 2.23 & 0.62 & $<0.001$ \\
\hline
\end{tabular}

Traits with coefficients of variation $(\mathrm{CVs}) \geq 0.3$ appear in bold type. Probability values ( $p$ value) were based on a GLM multivariate analysis of 171 genotypes and appear in bold if $\leq 0.01$ and italics if $\leq 0.05$ (see Table 2 for trait descriptions and units). Std. Dev., standard deviation.

Table 2. Description of 18 measured traits (13 global and five local traits) in 171 soybean genotypes grown in a semihydroponic phenotyping platform assessed at 39 days after sowing.

\begin{tabular}{|c|c|c|c|}
\hline Traits & Abbreviation & Description & Units \\
\hline \multicolumn{4}{|c|}{ Global traits (traits at the whole plant level) } \\
\hline Maximal root depth & MRD & Longest seminal root length, i.e., rooting depth & $\mathrm{cm}$ \\
\hline Root width & $\mathrm{RW}$ & Maximal horizontal extent of a root system (Figure 1c) & $\mathrm{cm}$ \\
\hline Root angle & RA & $\begin{array}{l}\text { Growth angle between two outer lateral roots } \\
\text { (Figure 1c) }\end{array}$ & Degree \\
\hline Total root length & RL & Total root length per plant & $\mathrm{cm}$ \\
\hline Root diameter & $\mathrm{RD}$ & Average diameter of root system per plant & $\mathrm{mm}$ \\
\hline Root mass & $\mathrm{RM}$ & Total dry mass of roots per plant & $\mathrm{mg}$ \\
\hline Specific root length & SRL & Total root length divided by root dry mass & $\mathrm{cm} \mathrm{mg}^{-1}$ \\
\hline Root tissue density & RTD & Total root dry mass divided by root volume & $\mathrm{mg} \mathrm{cm}^{-3}$ \\
\hline Root-shoot mass ratio & RSM & Total root dry mass divided by shoot dry mass & \\
\hline Leaf number & $\mathrm{LN}$ & Number of leaves per plant & \\
\hline Hypocotyl length & HL & $\begin{array}{l}\text { Length from cotyledon node to the origin on the } \\
\text { primary root }\end{array}$ & $\mathrm{cm}$ \\
\hline Shoot height & $\mathrm{SH}$ & $\begin{array}{l}\text { Shoot height (measured at its height from cotyledon node to } \\
\text { plant growth point) }\end{array}$ & $\mathrm{cm}$ \\
\hline Shoot mass & SM & Total shoot dry mass per plant & $\mathrm{mg}$ \\
\hline \multicolumn{4}{|c|}{ Local traits (traits at local level including ratios) } \\
\hline Root length-upper & RL-upper & Root length in upper $0-20 \mathrm{~cm}$ soil layer & $\mathrm{cm}$ \\
\hline Root length-lower & RL-lower & Root length below $20 \mathrm{~cm}$ depth & $\mathrm{cm}$ \\
\hline Root length in diameter fine & RL-fine & Root length of 'fine roots' (in diameter class < $0.5 \mathrm{~mm}$ ) & $\mathrm{cm}$ \\
\hline Root length in diameter coarse & RL-coarse & Root length of 'coarse roots' (diameter class $\geq 0.5 \mathrm{~mm}$ ) & $\mathrm{cm}$ \\
\hline Root length ratio & RLR-upper/lower & $\begin{array}{l}\text { Root length in top } 20 \mathrm{~cm} \text { soil layer divided by in root length } \\
\text { below } 20 \mathrm{~cm} \text { soil depth }\end{array}$ & $\mathrm{cm}$ \\
\hline
\end{tabular}

\footnotetext{
The same set of traits (except maximal root depth, root width, root angle, and leaf number) were measured in three soybean genotypes (\#054, \#055, and \#071) grown in soil-filled rhizoboxes assessed at 38 and 81 days after sowing. Root mass, root-shoot mass ratio, hypocotyl length, shoot height, and shoot mass were assessed 160 days after sowing.
} 

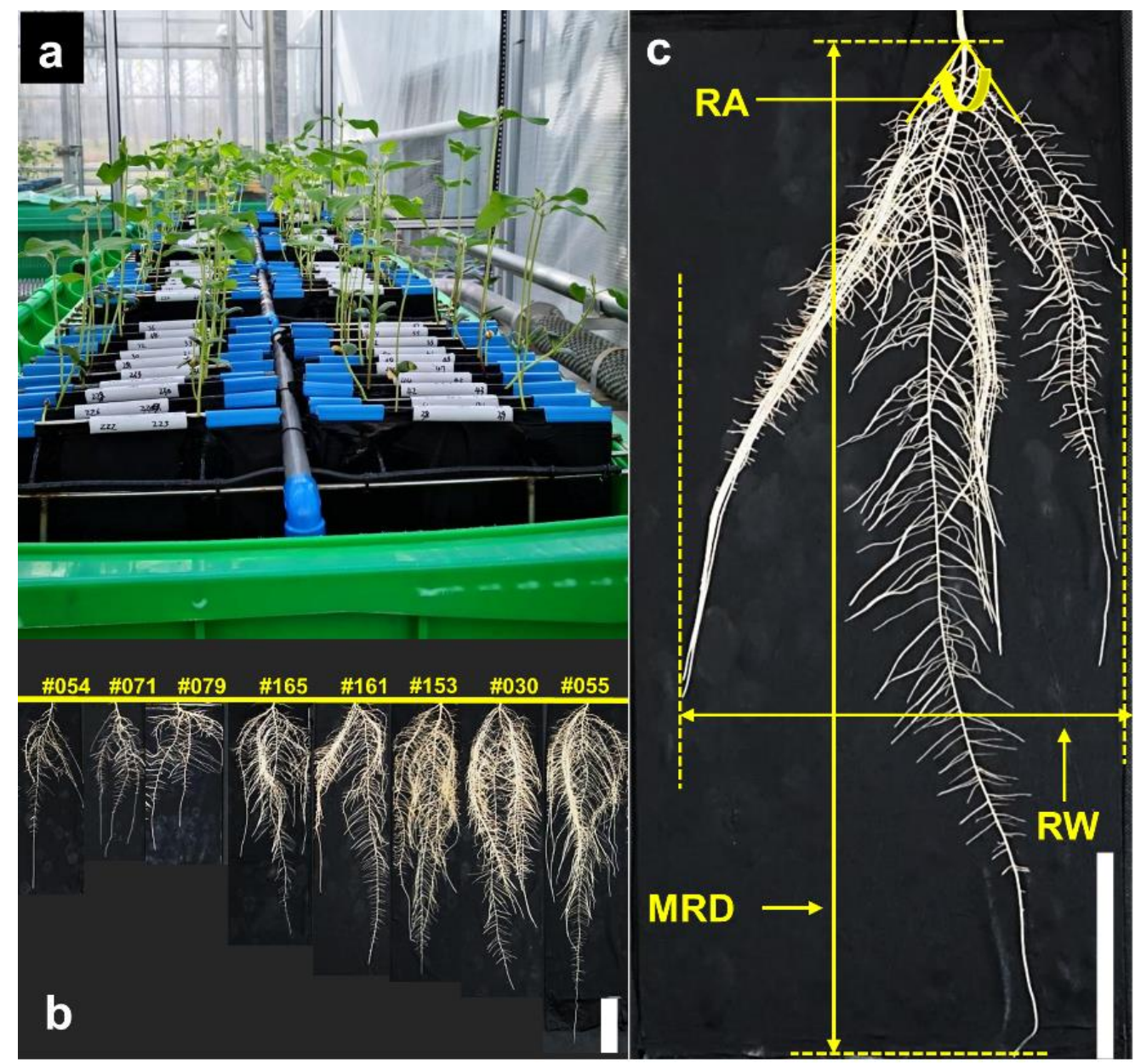

Figure 1. Layout of soybean plants grown in a semi-hydroponic phenotyping platform at 19 days after sowing (DAS) (a), and example images of root systems of eight selected genotypes at 39 DAS (b). Root angle (RA), root width (RW) and maximal root depth (MRD) of the soybean root system grown in a semi-hydroponic phenotyping platform (c), were measured at 39 DAS. White bar $=10 \mathrm{~cm}$.

Among the 68 genotypes from the northern Huaihe River region (NHHR), 29 genotypes had large root systems, 23 genotypes had medium root systems, and 16 genotypes had small root systems (Table S1). Among the 75 genotypes from the southern Huaihe River region (SHHR), 30 genotypes had large root systems, 17 genotypes had medium root systems, and 28 genotypes had small root systems (Table S1). Among the 28 parental lines (PL), 9 genotypes had large root systems, 5 genotypes had medium root systems, and 14 genotypes had small root systems (Table S1). The differences between the maximum and the minimum values of root mass, total root length, root length distribution of fine roots (diameter class $<0.5 \mathrm{~mm}$ ), and coarse roots (diameter class $\geq 0.5 \mathrm{~mm}$ ) were more profound than those of NHHR and SHHR genotypes, respectively (Figure S1).

Variation also occurred for maximal rooting depth, root width, root angle, average root diameter, and root-shoot mass ratio. Genotype \#001 had the greatest maximal rooting depth $(65 \mathrm{~cm})$ per plant, which was 2.3 -fold deeper than the shortest rooting depth $(28.8 \mathrm{~cm}$, $\# 079$ ). Root width ranged from 9.57 (\#002) to 20.5 (\#120) cm per plant. Root angle ranged from $63^{\circ}$ (\#171) to $160^{\circ}$ (\#068), with about $84 \%$ of the 171 genotypes $>90^{\circ}$. Average root diameter ranged from 0.20 (\#079) to 0.47 (\#077) mm per plant, and the root-shoot mass ratio ranged from 0.11 (\#168) to 0.32 (\#034) (Table 1).

At harvest (39 DAS), six genotypes had three trifoliate leaves, and five genotypes had six trifoliate leaves. The longest hypocotyl length was 9.1 (\#131) cm per plant, and the shortest hypocotyl length was 2.2 (\#014) cm per plant. Shoot height ranged from 18.7 (\#071) 
to 86.7 (\#023) cm per plant, with about $56 \%$ of the 171 genotypes $>51 \mathrm{~cm}$. Shoot mass ranged from 164 (\#071) to 1150 (\#023) mg per plant (Table 1).

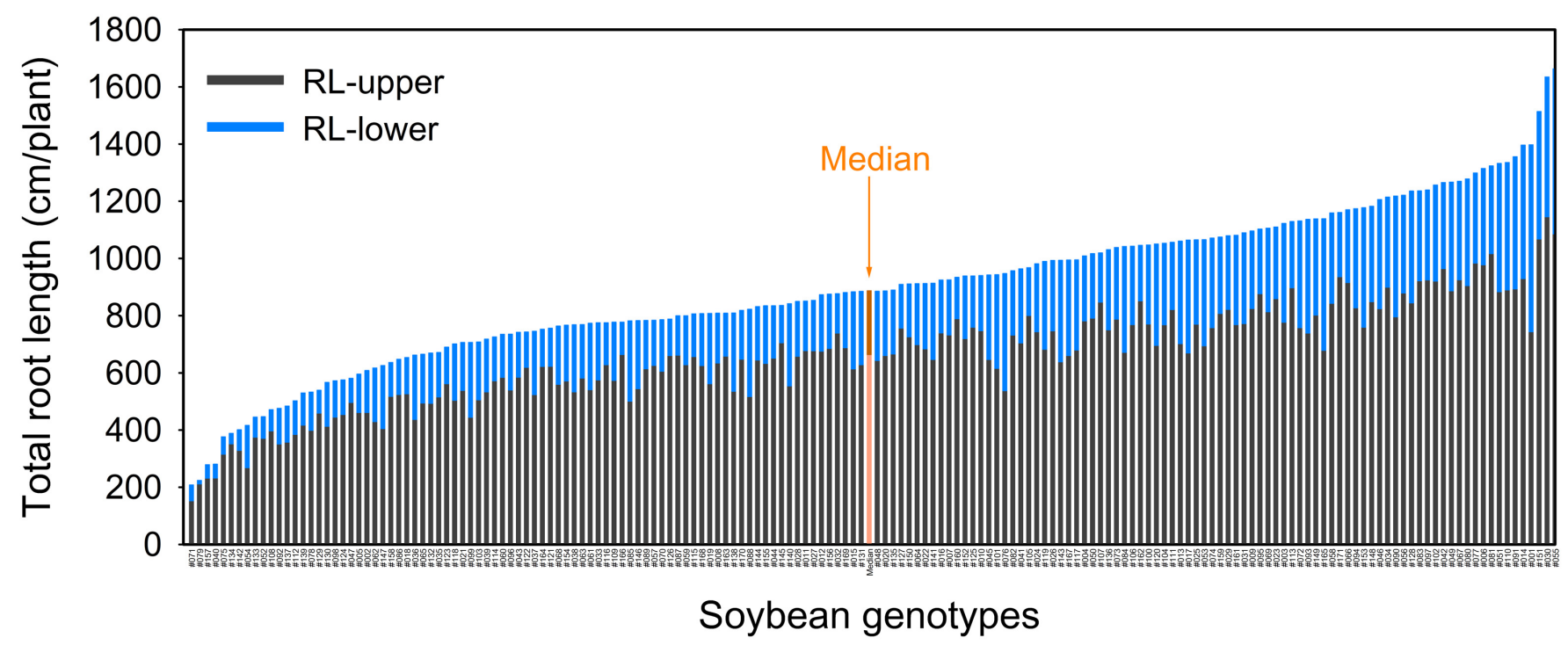

Figure 2. Stacked vertical barplot showing genotypic variation in root length of 171 soybean genotypes grown in a semihydroponic phenotyping platform 39 days after sowing. Median values were plotted for all genotypes. Both RL-upper (root length in 0-20 cm soil layer) and RL-lower (root length below $20 \mathrm{~cm}$ soil depth) are presented (ordered from shortest to longest average total root length).

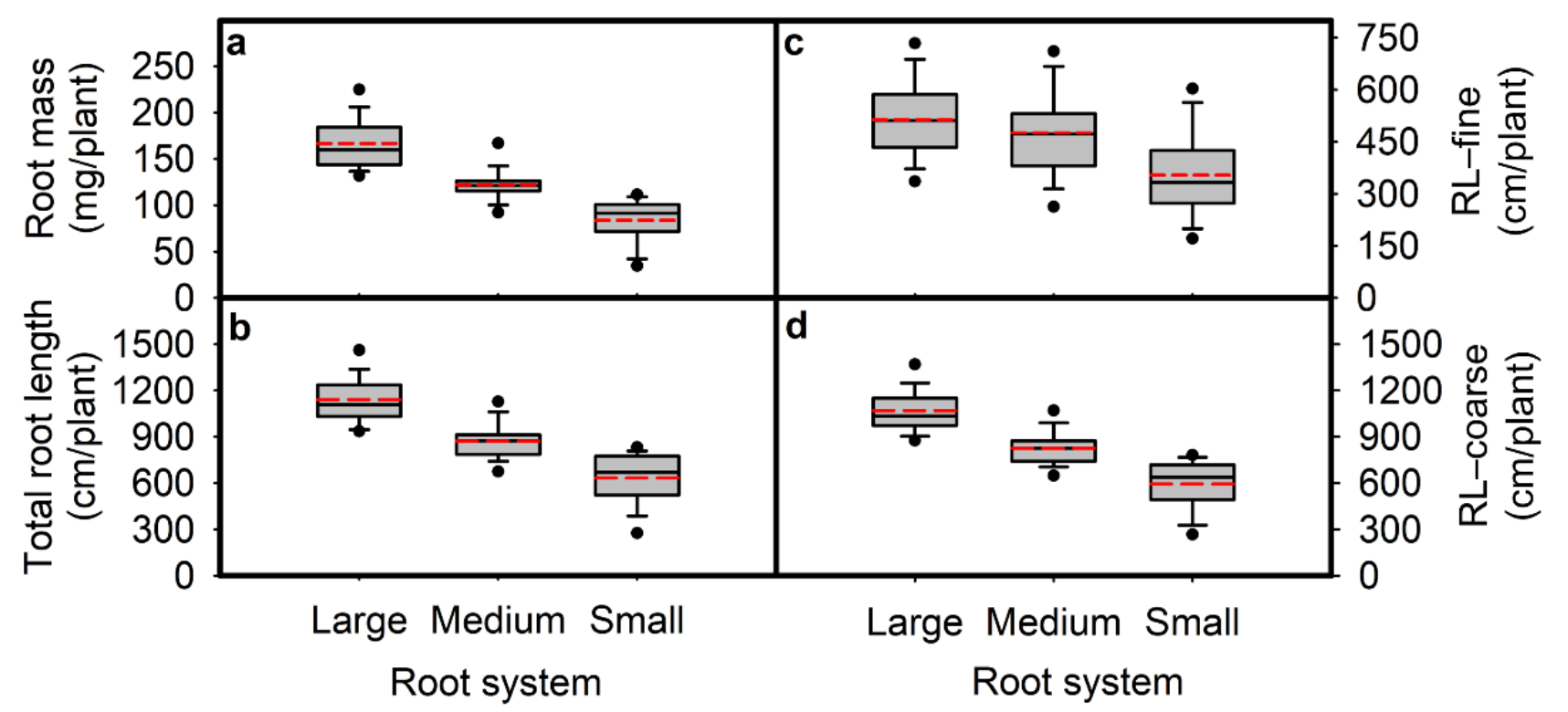

Figure 3. Root mass (RM; (a)), total root length (RL; (b)), root length in diameter fine (RL-fine; (c)) and root length in diameter coarse (RL-coarse; (d)) for genotypes in three root size categories large (68 genotypes), medium (45 genotypes), and small (58 genotypes). The 171 genotypes were grown in a semi-hydroponic phenotyping platform 39 days after sowing. Significant differences are shown for the three root size categories $(p \leq 0.05)$. The whiskers, box, and dot are determined by the 5th and 95th percentiles, 25th and 75th percentiles, and the 1st and 99th percentiles, respectively. The line and dashed inside the box marks are the median and mean, respectively.

\subsubsection{Local Traits}

Root traits at different depths and root lengths in different diameter classes (Tables 1 and 2) varied significantly with CVs $\geq 0.3$. The root length (upper), root length in the upper $0-20 \mathrm{~cm}$ soil layer, ranged from 152 (genotype \#071) to 1146 (\#030) cm per plant $(\mathrm{CV}=0.34)$. Root length 
(lower), root length below $20 \mathrm{~cm}$ soil depth, ranged from 11.5 (\#079) to 654 (\#001) cm per plant (CV = 0.58). Root length (fine), diameter class $<0.5 \mathrm{~mm}$, ranged from 134 (\#079) to 908 (\#165) $\mathrm{cm}$ per plant $(\mathrm{CV}=0.46)$. Root length (coarse), diameter class $\geq 0.5 \mathrm{~mm}$, ranged from 175 (\#071) to 1551 (\#055) $\mathrm{cm}$ per plant $(\mathrm{CV}=0.37)$. Root length ratio-upper/lower ranged from 1.18 (\#001) to 16.5 (\#079) $(\mathrm{CV}=0.62$, all $p<0.01$; Table 1$)$. For the combined data of the 171 genotypes, more than $70 \%$ of the root length was in the $0-20 \mathrm{~cm}$ soil layer (Table 1, Figure 2).

Root diameter data showed that soybean plants had relatively fine roots with an average root diameter $<0.5 \mathrm{~mm}$ for all genotypes (Table 1 ). Most of the root length came from coarse roots ( $>0.5 \mathrm{~mm}$ diameter class), accounting for $65 \%$ of the total root length. Root length (fine) contributed $35 \%$ to the total root length (Table 1).

\subsubsection{Correlation among Traits}

A subset of nine traits, including eight root traits and one shoot trait (shoot mass), with $\mathrm{CV} \geq 0.3$ (Table 1), were selected for Pearson's correlation analysis to identify relationships among the traits. Most of the selected traits had strong correlations with the other traits (Table 3). Total root length, root mass, shoot mass, and root length ratio-upper/lower were strongly associated with all other traits (mostly $p \leq 0.01$ ) except for the specific root length.

Table 3. Pearson's correlation matrix for eight root traits (RL, SRL, RL-upper, RL-lower, RL-fine, RL-coarse, and RLRupper/lower) and one shoot trait (SM) in 171 soybean genotypes grown in a semi-hydroponic phenotyping platform assessed 39 days after sowing.

\begin{tabular}{|c|c|c|c|c|c|c|c|c|}
\hline- & RM & SRL & SM & $\begin{array}{l}\text { RL- } \\
\text { Upper }\end{array}$ & $\begin{array}{l}\text { RL- } \\
\text { Lower }\end{array}$ & $\begin{array}{l}\text { RL- } \\
\text { Fine }\end{array}$ & $\begin{array}{l}\text { RL- } \\
\text { Coarse }\end{array}$ & $\begin{array}{l}\text { RLR- } \\
\text { Upper/ } \\
\text { Lower }\end{array}$ \\
\hline RL & $0.903^{* *}$ & $-0.023 \mathrm{~ns}$ & $0.818^{* *}$ & $0.955^{* *}$ & $0.867^{* *}$ & $0.593 * *$ & $0.998 * *$ & $-0.469^{* *}$ \\
\hline $\mathrm{RM}$ & - & $-0.322^{* *}$ & $0.803^{* *}$ & $0.868^{* *}$ & $0.774^{* *}$ & $0.505^{* *}$ & $0.900 * *$ & $-0.429^{* *}$ \\
\hline SRL & - & - & $-0.101 \mathrm{~ns}$ & $-0.055 \mathrm{~ns}$ & $0.034 \mathrm{~ns}$ & $-0.022 \mathrm{~ns}$ & $-0.033 \mathrm{~ns}$ & $-0.014 \mathrm{~ns}$ \\
\hline SM & - & - & - & $0.812 * *$ & $0.657^{* *}$ & $0.599^{* *}$ & $0.820 * *$ & $-0.404^{* *}$ \\
\hline RL-upper & - & - & - & - & $0.680 * *$ & $0.509 * *$ & $0.951 * *$ & $-0.303^{* *}$ \\
\hline RL-lower & - & - & - & - & - & $0.610 * *$ & $0.869^{* *}$ & $-0.650^{* *}$ \\
\hline RL-fine & - & - & - & - & - & - & $0.608 * *$ & $-0.514^{* *}$ \\
\hline RL-coarse & - & - & - & - & - & - & - & $-0.474^{* *}$ \\
\hline
\end{tabular}

Traits with CVs $\geq 0.3$ were included in the analysis (Table 1 ). Correlation is significant if $p \leq 0.01\left({ }^{* *}\right)$; ns, no significance (see Table 2 for trait descriptions and units).

For example, the total root length was positively correlated with root length (upper) $\left(R^{2}=0.912\right.$; Figure $\left.4 d\right)$, root length (lower) $\left(R^{2}=0.752\right.$; Figure $\left.4 d\right)$, root length (fine) $\left(R^{2}=0.352\right.$; Figure $4 \mathrm{c}$ ), and root length (coarse) $\left(\mathrm{R}^{2}=0.997\right.$; Figure $4 \mathrm{c}$ ) (all $p \leq 0.01$; Table 3$)$. Root mass was positively correlated with total root length, root lengths (upper/lower), root lengths (coarse/fine), and negatively correlated with specific root length (all $p \leq 0.01$; Table 3). Shoot mass was positively correlated with total root length $\left(R^{2}=0.669\right.$; Figure $\left.4 a\right)$ and root mass $\left(R^{2}=0.646\right.$; Figure $\left.4 b\right)$ (all $p \leq 0.01$; Table 3$)$. Root length (upper) was positively correlated with root length (lower) and root lengths (coarse/fine) (all $p \leq 0.01$; Table 3). Specific root length was negatively correlated with total root length and shoot mass (Table 3). There were strong negative correlations between the root length ratio-upper/lower and all other traits except for the specific root length (Table 3). 


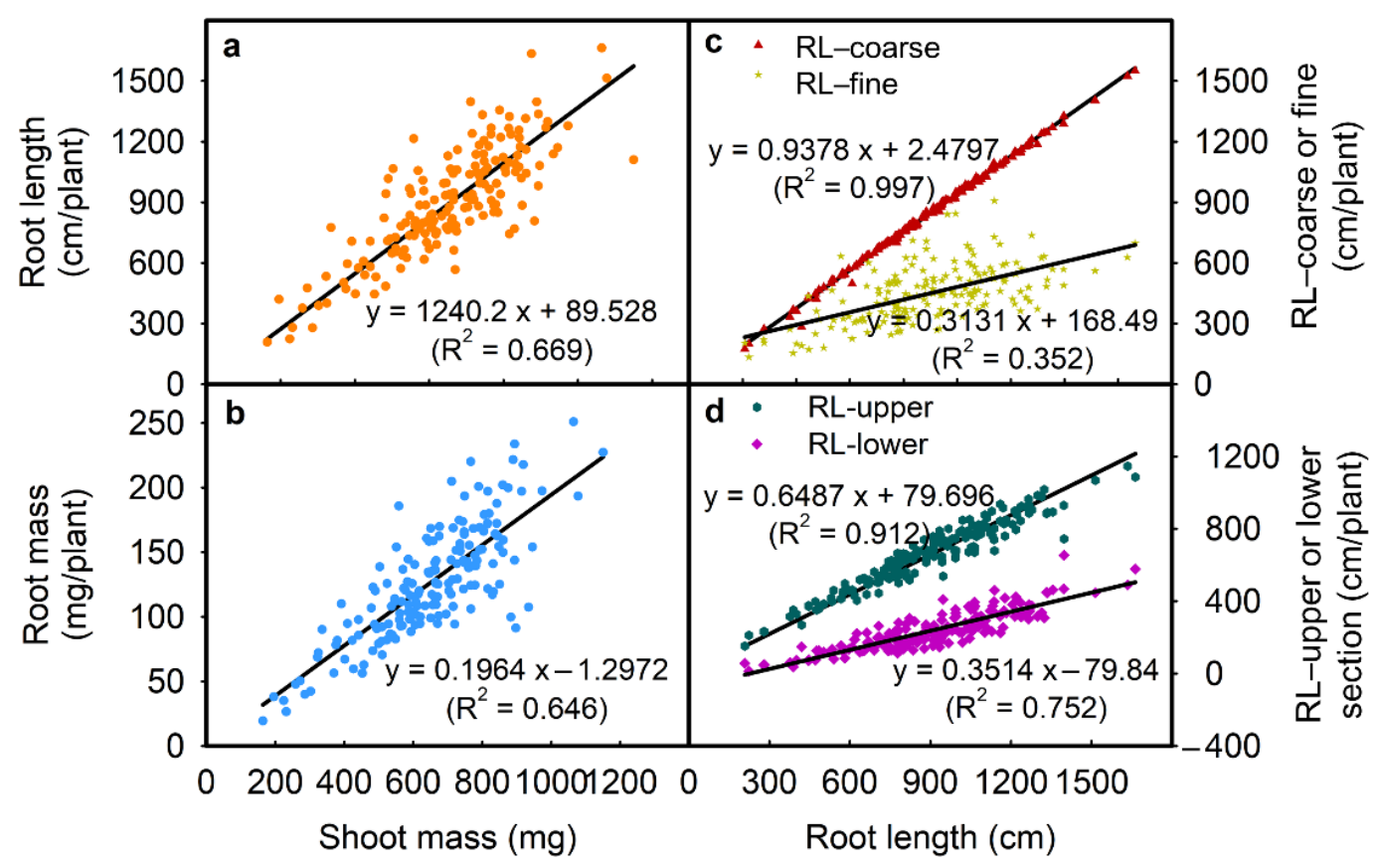

Figure 4. Correlation between (a) shoot mass and root length, (b) shoot mass and root mass, (c) root length and RL-coarse or RL-fine, and (d) root length and RL-upper or RL-lower in 171 soybean genotypes grown in a semi-hydroponic phenotyping platform 39 days after sowing. Each dot represents the mean values of three replicates.

\subsubsection{Root Trait Variability}

Eight root traits and shoot mass with $C V s \geq 0.3$ (Table 1) were included in the PCA. Two principal components (PCs) were identified with eigenvalues $>1$, capturing $78.9 \%$ of the total variation in root system architectural traits across the 171 soybean genotypes (Table 4). The first component (PC1) represented $66.2 \%$ of the variability and influenced by most root traits (total root length, root mass, root length-upper/lower, root lengths in diameter coarse, root lengths in diameter fine, root length ratio-upper/lower), and shoot mass (Table 4, Figure 5). PC2 represented $12.6 \%$ of the total variation and was influenced by the specific root length (Table 4, Figure 5).

Table 4. Principal component analysis of nine selected traits with $C V \geq 0.3$ and the proportion of variation in each principal component.

\begin{tabular}{lll}
\hline Traits & PC1 & PC2 \\
\hline RL & 0.976 & -0.016 \\
RM & 0.917 & -0.309 \\
SRL & -0.083 & 0.883 \\
SM & 0.870 & -0.106 \\
RL-upper & 0.907 & -0.143 \\
RL-lower & 0.889 & 0.199 \\
RL-fine & 0.701 & 0.212 \\
RL-coarse & 0.978 & -0.018 \\
RLR-upper/lower & -0.585 & -0.383 \\
\hline Eigenvalue & 5.96 & 1.14 \\
Variability (\%) & 66.2 & 12.6 \\
Cumulative (\%) & 66.2 & 78.9 \\
\hline
\end{tabular}

See Table 2 for trait descriptions and units. 


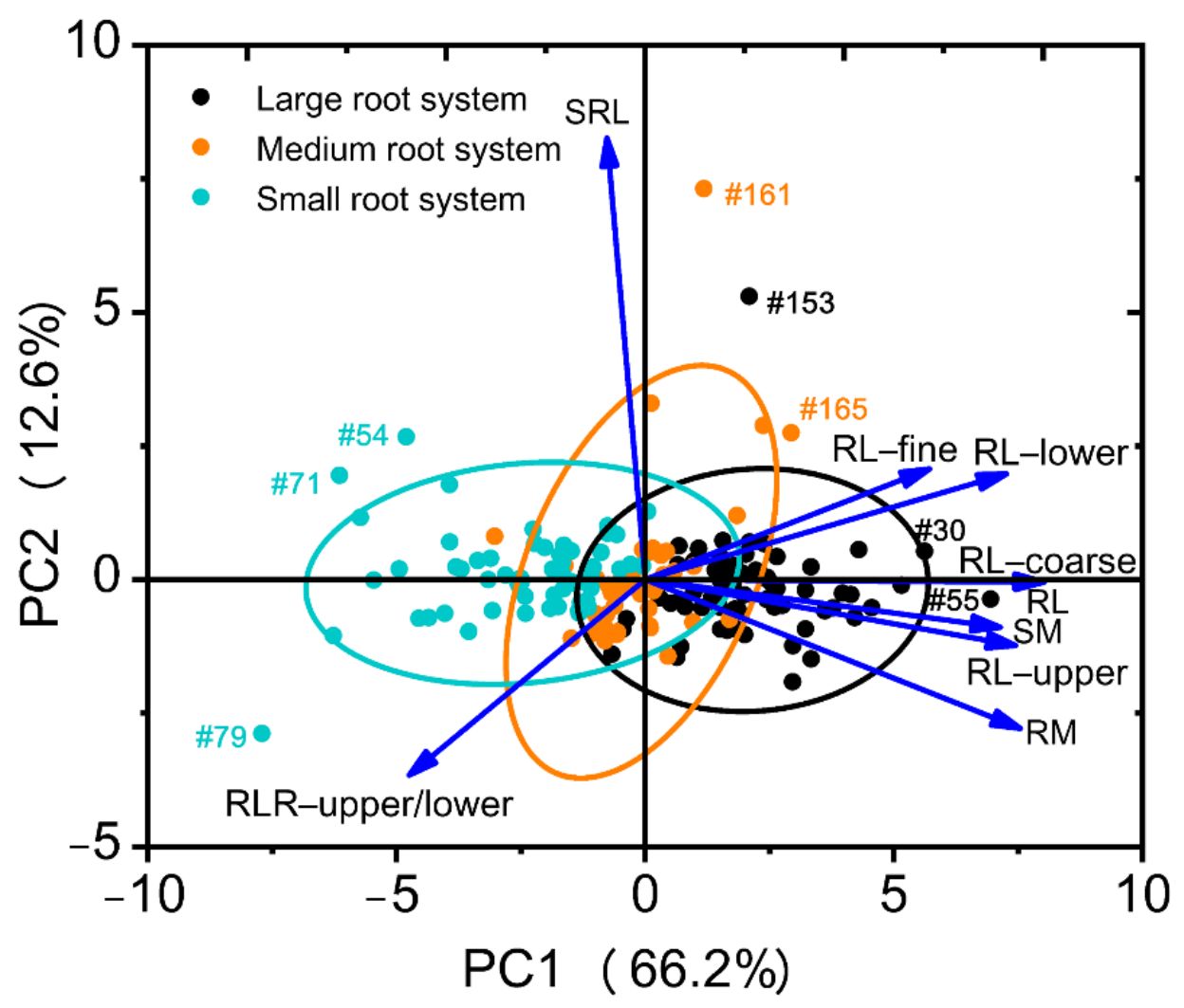

Figure 5. Principal component analysis of nine selected traits with $C V s \geq 0.3$ across 171 soybean genotypes grown in a semi-hydroponic phenotyping platform 39 days after sowing. The position of each trait is shown for PC1 vs. PC2 representing 78.9\% of the total variability. The genotypes with extreme traits (outliers) are indicated by genotype number.

Genotype distribution based on PCA regression scores of the nine selected traits is shown in a biplot (Figure 5), exhibiting clear separation of the three root size categories and a positive contribution of all selected traits, except for the specific root length and root length ratio (upper/lower) (Figure 5). Of the selected nine traits, root length, root mass, root length (upper), and root length (coarse) contributed the most to root size. The genotypes with extreme traits (outliers) are shown in the biplot (genotype \#030, \#054, \#055, $\# 071, \# 079, \# 153, \# 161$ and \#165) (Figure 5). In the PCA biplot based on the three source categories, genotypes \#071, \#079, \#153, \#161, and \#165 also had extreme traits (outliers) (Figure S2). The same outer genotypes with extreme traits in two biplots should be selected for further study.

\subsubsection{Genotype Homogeneous Grouping Based on Root Trait Variation}

An agglomerative hierarchical clustering (AHC) dendrogram was constructed using the Euclidean distance as the interval measurement on nine selected traits with $\mathrm{CVs} \geq 0.3$ and exhibits large diversity in traits among 171 soybean genotypes (Figure 6). The 171 soybean genotypes were separated into five main clusters/groups (G1 to G5), revealing variation in the degree of homogeneity among tested genotypes. Representative genotypes from each group were selected and used in further studies. Group 1 contained 56 genotypes, including 52 with a large root system and four with a medium root system. Group 2 contained one genotype (genotype \#165) with a medium root system. Group 3 contained 13 genotypes with a large root system, 39 with a medium root system, and 38 with a small root system. Group 4 contained one genotype with a medium root system and 20 with a small root system. Group 5 contained three genotypes (genotype \#030, \#055 and \#151) with a large root system. These results demonstrate that genotypes from the same root size were not always clustered into the same or closer group(s). 


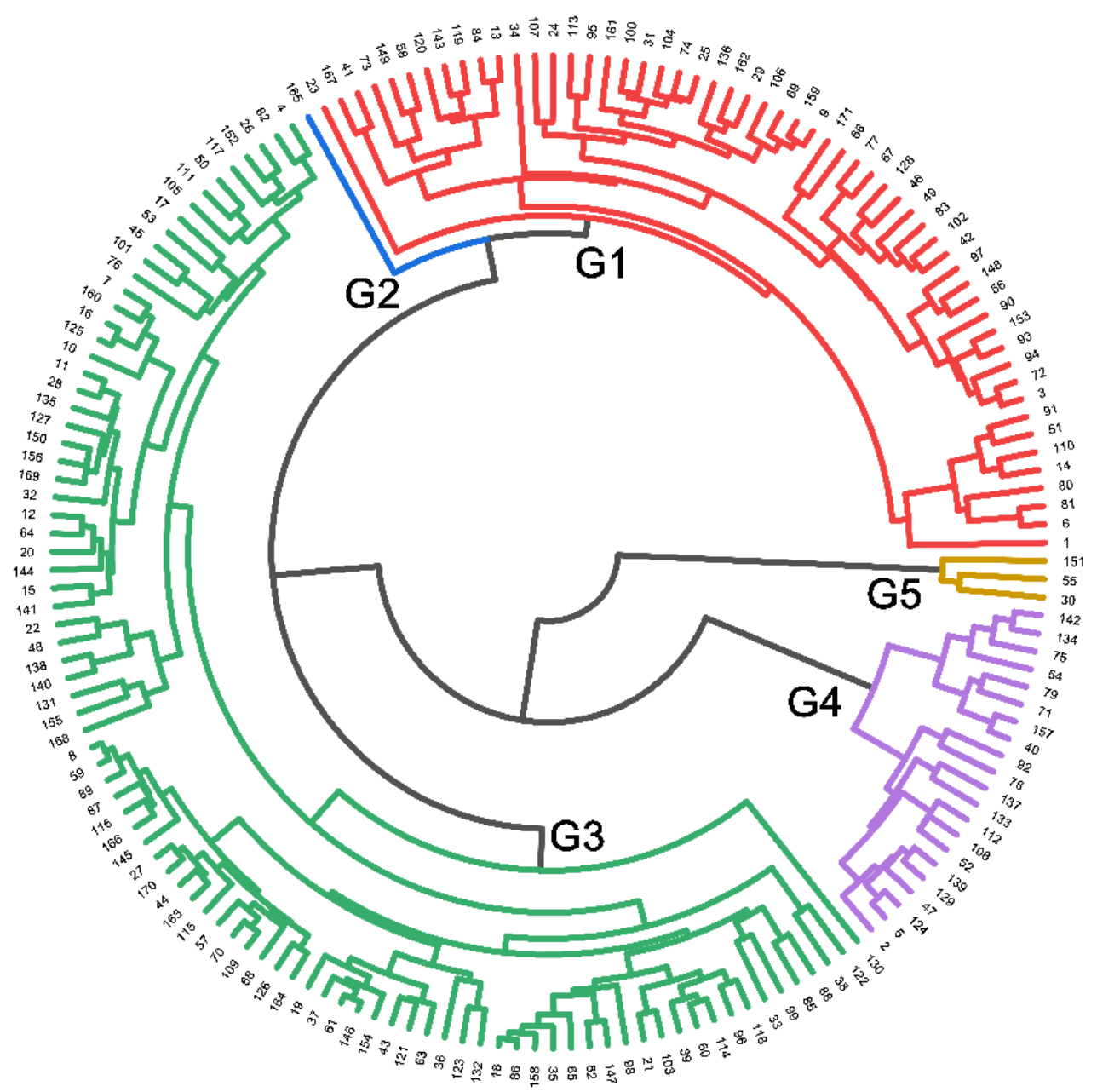

Figure 6. Dendrogram of agglomerative hierarchical clustering (AHC) using the average linkage method with Euclidean distance as the interval measurement on nine selected traits with CVs $\geq 0.3$. The 171 soybean genotypes were assigned to five groups (G1 to G5). The nine traits are the same as those used for PCA in Table 4 (the semi-hydroponic system).

\subsection{Validation of Root Characters in Rhizoboxes}

\subsubsection{Phenotypes in Rhizoboxes}

Three genotypes with putative differences in root system size were selected in a followup validation experiment. Genotypes \#054 and \#071 had small root systems, and \#055 had a large root system (Figure 7). Large variation was found for the total root length, root mass, specific root length, root-shoot mass ratio, hypocotyl length, shoot height, shoot mass, and five local root traits (Table 5). There was no significant difference in root diameter (Table 5). Genotype \#055 had the longest total root length and greatest root mass and shoot mass relative to \#054 and \#071, confirming the observations in the semi-hydroponic system (Table 5, Figure 8). From the seedling to flowering stage, genotype \#055 produced significantly more roots than the other two genotypes (Figure 9). Genotype \#055 (large root system) had flowered earlier than \#054 and \#071 (small root system) (Figure 9). 


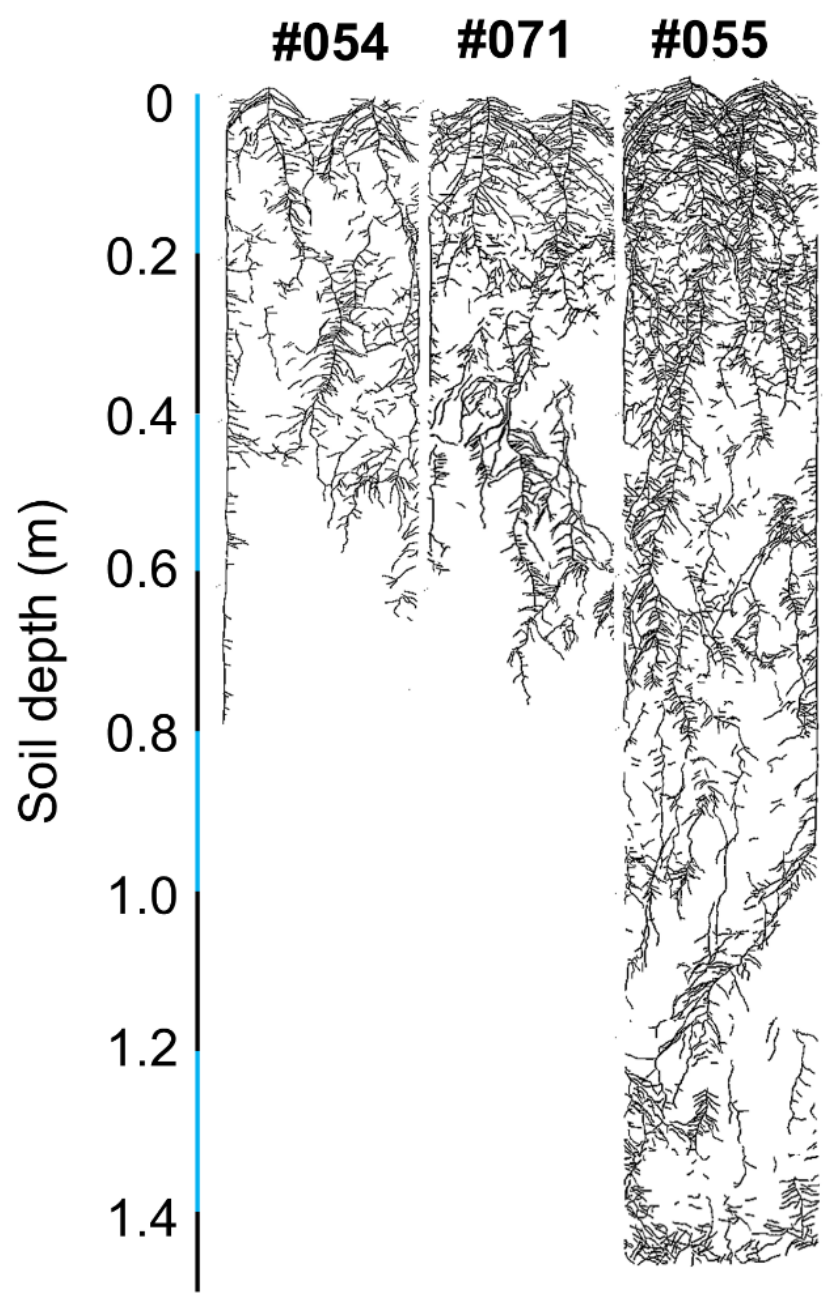

Figure 7. Scanned image of traced root systems on the glass panels of the rhizoboxes for soybean genotypes \#054, \#055, and \#071 at 93 days after sowing.

Table 5. Mean values of 13 measured traits (eight global and five local traits) in three soybean genotypes (\#054, \#055, and \#071) grown in soil-filled rhizoboxes at 38 days after sowing (DAS), 81 DAS, and 160 DAS. At 160 DAS, only root mass $(\mathrm{RM})$, root-shoot mass ratio (RSM), hypocotyl length (HL), shoot height (SH), and shoot mass (SM) were measured.

\begin{tabular}{|c|c|c|c|c|c|c|c|c|c|c|}
\hline \multirow{2}{*}{ Trait } & \multirow{2}{*}{ Unit } & \multicolumn{3}{|c|}{38 DAS } & \multicolumn{3}{|c|}{81 DAS } & \multicolumn{3}{|c|}{160 DAS } \\
\hline & & \#054 & $\# 055$ & \#071 & \#054 & $\# 055$ & $\# 071$ & \#054 & \#055 & \#071 \\
\hline $\mathrm{RM}$ & g plant ${ }^{-1}$ & $0.59 \mathrm{~b}$ & $1.10 \mathrm{a}$ & $0.89 \mathrm{ab}$ & $1.11 \mathrm{~b}$ & $2.32 \mathrm{a}$ & $1.78 \mathrm{ab}$ & $6.70 \mathrm{~b}$ & $12.5 \mathrm{a}$ & $2.36 \mathrm{c}$ \\
\hline RSM & - & $0.41 \mathrm{~b}$ & $0.46 \mathrm{ab}$ & $0.59 \mathrm{a}$ & $0.23 \mathrm{~b}$ & $0.31 \mathrm{a}$ & $0.27 \mathrm{ab}$ & $0.30 \mathrm{~ns}$ & $0.30 \mathrm{~ns}$ & $0.20 \mathrm{~ns}$ \\
\hline $\mathrm{HL}$ & $\mathrm{cm}$ & $4.25 \mathrm{~b}$ & 8.17 a & $5.92 \mathrm{~b}$ & $4.05 \mathrm{~b}$ & $7.50 \mathrm{a}$ & $7.00 \mathrm{a}$ & $5.00 \mathrm{~b}$ & $7.67 \mathrm{a}$ & $6.42 \mathrm{ab}$ \\
\hline $\mathrm{SH}$ & $\mathrm{cm}$ & $98.0 \mathrm{ab}$ & 107 a & $80.5 \mathrm{~b}$ & $100 \mathrm{ab}$ & $114 \mathrm{a}$ & $88.5 \mathrm{~b}$ & $108 \mathrm{ab}$ & $121 \mathrm{a}$ & $93.3 \mathrm{~b}$ \\
\hline SM & g plant ${ }^{-1}$ & $1.48 \mathrm{~b}$ & $2.38 \mathrm{a}$ & $1.50 \mathrm{~b}$ & $4.90 \mathrm{~b}$ & $7.47 \mathrm{a}$ & $6.48 \mathrm{ab}$ & $22.1 \mathrm{ab}$ & $41.7 \mathrm{a}$ & $11.6 \mathrm{~b}$ \\
\hline RL & $\mathrm{m}$ & $36.6 \mathrm{~b}$ & $74.0 \mathrm{a}$ & $43.7 \mathrm{~b}$ & $70.2 \mathrm{~b}$ & $161 \mathrm{a}$ & $75.3 \mathrm{~b}$ & - & - & - \\
\hline RD & $\mathrm{mm}$ & $0.39 \mathrm{~ns}$ & $0.41 \mathrm{~ns}$ & $0.40 \mathrm{~ns}$ & $0.44 \mathrm{~ns}$ & $0.43 \mathrm{~ns}$ & $0.42 \mathrm{~ns}$ & - & - & - \\
\hline SRL & $\mathrm{m} \mathrm{g}^{-1}$ & $6.17 \mathrm{ab}$ & $6.76 \mathrm{a}$ & $4.94 \mathrm{~b}$ & $6.34 \mathrm{ab}$ & $6.93 \mathrm{a}$ & $4.24 \mathrm{~b}$ & - & - & - \\
\hline RL-upper & $\mathrm{m}$ & $36.0 \mathrm{~b}$ & $71.0 \mathrm{a}$ & $40.4 \mathrm{~b}$ & $62.7 \mathrm{~b}$ & $124 \mathrm{a}$ & $60.7 \mathrm{~b}$ & - & - & - \\
\hline RL-lower & $\mathrm{m}$ & $0.32 \mathrm{~b}$ & $3.04 \mathrm{a}$ & $3.31 \mathrm{a}$ & $7.54 \mathrm{~b}$ & $37.3 \mathrm{a}$ & $14.6 \mathrm{~b}$ & - & - & - \\
\hline RL-fine & $\mathrm{m}$ & $30.5 \mathrm{~b}$ & $62.7 \mathrm{a}$ & $36.2 \mathrm{~b}$ & $57.4 \mathrm{~b}$ & $134 \mathrm{a}$ & $62.1 \mathrm{~b}$ & - & - & - \\
\hline RL-coarse & $\mathrm{m}$ & $5.83 \mathrm{~b}$ & $11.2 \mathrm{a}$ & $7.52 \mathrm{ab}$ & $12.8 \mathrm{~b}$ & $27.5 \mathrm{a}$ & $13.2 \mathrm{~b}$ & - & - & - \\
\hline $\begin{array}{l}\text { RLR- } \\
\text { upper/lower }\end{array}$ & $\mathrm{m}$ & $116 \mathrm{a}$ & $25.9 \mathrm{~b}$ & $12.4 \mathrm{~b}$ & $16.5 \mathrm{a}$ & $3.39 \mathrm{~b}$ & $5.17 \mathrm{~b}$ & - & - & - \\
\hline
\end{tabular}

For each trait, data with the same letter indicate no significant difference between cultivars ( $p \leq 0.05$, see Table 2 for trait descriptions), ns, no significance. 


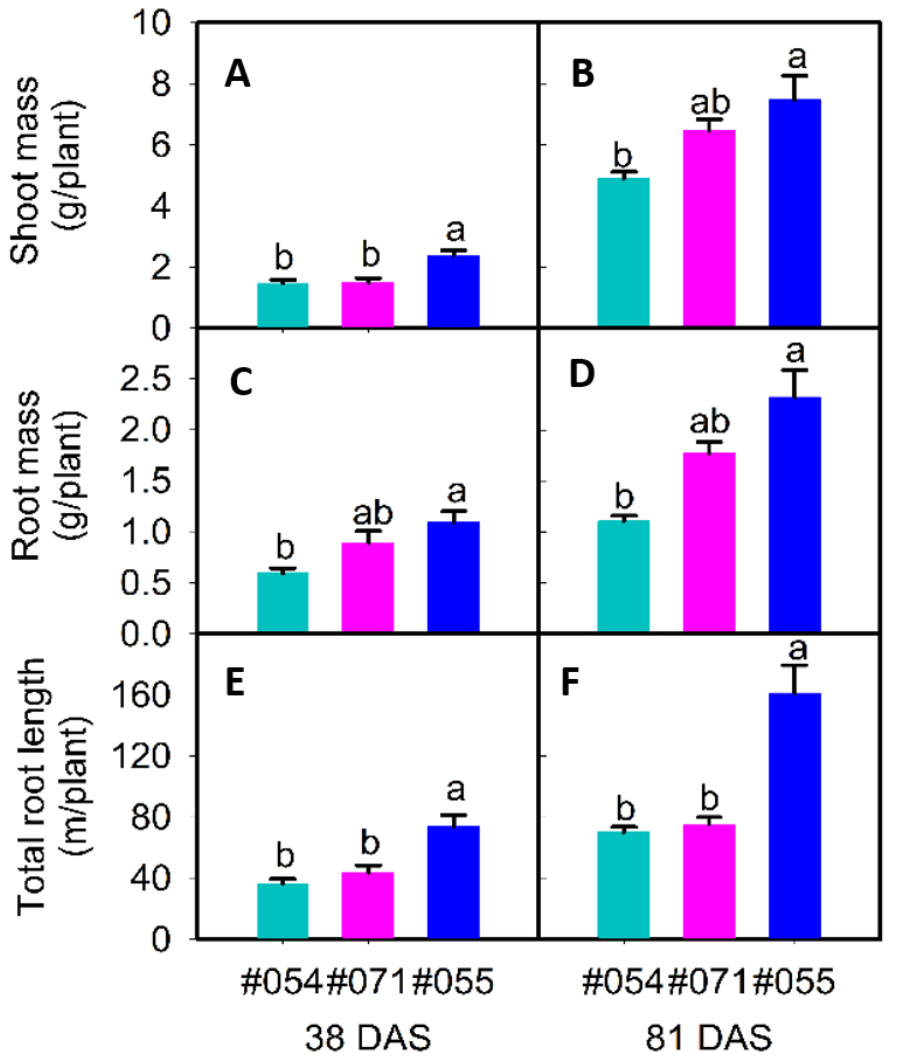

Figure 8. Shoot mass $(\mathbf{A}, \mathbf{B})$, root mass $(\mathbf{C}, \mathbf{D})$, and total root length $(\mathbf{E}, \mathbf{F})$ of three soybean genotypes (\#054, \#055, and \#071) 38 days after sowing (DAS) ((A,C,E), R1 growth stage except \#054, which was about $44 \mathrm{DAS})$ and $81 \mathrm{DAS}((\mathbf{B}, \mathbf{D}, \mathbf{F})$, all genotypes at $\mathrm{R} 5$ growth stage) grown in soil-filled rhizoboxes. For each trait, mean data $(+\mathrm{SE}, n=3)$ with different letters indicate significant difference among the three genotypes $(p \leq 0.05)$.

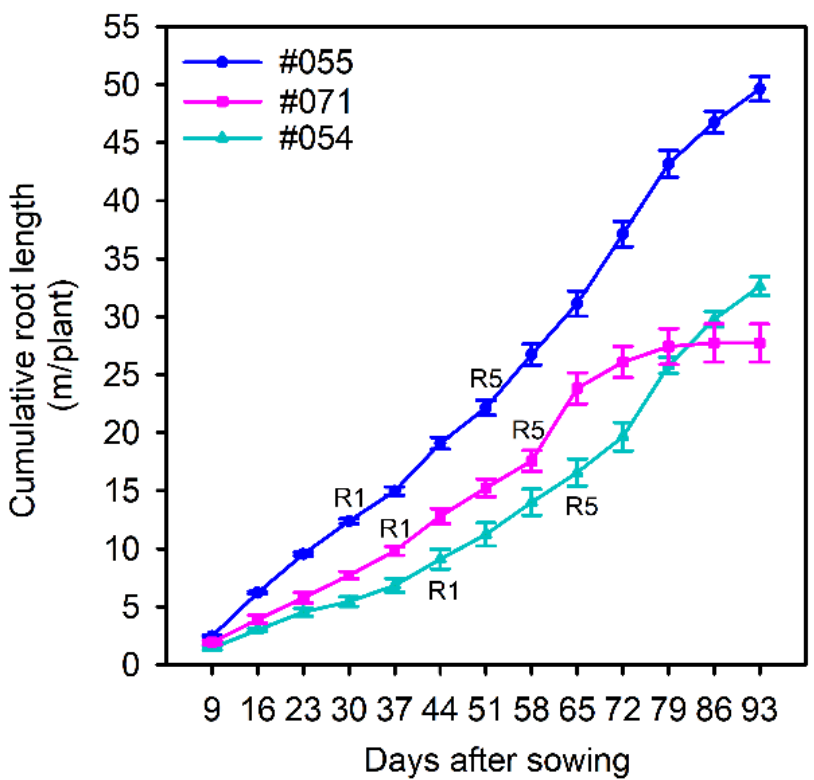

Figure 9. Cumulative root length of three soybean genotypes (\#054, \#055, and \#071) from nine days after sowing (DAS) to 93 DAS (the rhizobox system). Genotype \#054 and \#071 have small root systems and \#055 has a large root system (soybean growth stage: R1-time to flowering; R5-time to forming seed pods). 
At 38 DAS, the root length (upper) significantly differed in the three genotypes (Table 5). The total root length ranged from $36.6 \mathrm{~m}$ per plant in \#054 to $74.0 \mathrm{~m}$ per plant in \#055 (Table 5). Genotype \#055 had 1.8-fold and 1.2-fold more root mass than \#054 and \#071, respectively (Table 5, Figure 8c). Genotype \#055 had 1.9-fold and 1.5-fold more root length (coarse) than \#054 and \#071 (Table 5). At all assessment times, most of the traits were strongly correlated ( $p \leq 0.01$; Table 6 ). Root mass and hypocotyl length were strongly associated with all other traits except for the rooting depth, specific root length, root-shoot mass ratio, and shoot height (mostly $p \leq 0.01$; Table 6 ). For example, root mass had positive correlations with root length, root length (upper), and root length (coarse). Root length ratio (upper/lower) had negative correlations with root mass, root-shoot mass ratio, and root length (lower). The experiment confirmed that phenotypic variation in root size at the seedling stage (39 DAS) in a phenotyping study using the semi-hydroponic system was reproducible at the seedling stage (38 DAS) in a validation experiment using rhizoboxes.

At 81 DAS, the three genotypes significantly differed for root mass, total root length, shoot mass, root lengths (upper/lower), and root lengths (coarse/fine) (Table 5). In particular, genotype \#055 had double the total root length and root length (fine) of \#054 and \#071 (Table 5). Genotype \#055 also had 2.1-fold and 1.3-fold more root mass (Table 5, Figure 8d) and 1.5-fold and 1.2-fold more shoot mass than \#054 and \#071, respectively (Table 5, Figure 8 b). At all assessment times, most root traits were strongly correlated $(p \leq 0.01$; Table 6$)$. For example, root length and root mass had strong correlations with shoot mass, root lengths (upper/lower), and root lengths (coarse/fine) ( $p \leq 0.01$; Table 6). The root length ratio (upper/lower) was not significantly correlated with other traits (Table 6).

At 160 DAS, root mass, hypocotyl length, shoot height, and shoot mass significantly differed between the three genotypes (Table 5). Genotype \#055 had 1.9-fold and 5-fold more root mass, 1.9-fold and 3.6-fold more shoot mass, and 1.9-fold and 3.6-fold more shoot height than \#054 and \#071, respectively (Table 5). The three genotypes showed no significant difference in seed yield, although genotype \#054 had more seeds and pods than the other two genotypes (data not presented). 


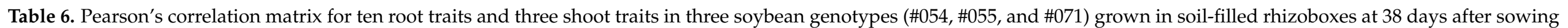
(lower left section) and 81 days after sowing (upper right section).

\begin{tabular}{|c|c|c|c|c|c|c|c|c|c|c|c|c|c|}
\hline- & RL & RD & $\mathbf{R M}$ & SRL & RSM & HL & SH & SM & RL-Upper & RL-Lower & RL-Fine & RL-Coarse & $\begin{array}{c}\text { RLR- } \\
\text { Upper/Lower }\end{array}$ \\
\hline RL & - & 0.116 & $0.879 * *$ & 0.591 & 0.750 * & 0.637 & 0.583 & $0.807 * *$ & $0.991 * *$ & $0.958^{* *}$ & $0.990^{* *}$ & $0.858 * *$ & -0.385 \\
\hline $\mathrm{RD}$ & 0.377 & - & 0.053 & 0.181 & 0.256 & -0.014 & 0.187 & -0.107 & 0.073 & 0.201 & 0.129 & 0.031 & -0.033 \\
\hline SRL & 0.504 & -0.271 & 0.020 & - & 0.117 & -0.161 & 0.769 * & 0.065 & 0.651 & 0.425 & 0.602 & 0.451 & 0.108 \\
\hline RSM & 0.012 & 0.408 & 0.459 & -0.785 * & - & $0.819^{* *}$ & 0.333 & 0.670 * & 0.694 * & $0.827 * *$ & 0.762 * & 0.574 & -0.552 \\
\hline HL & $0.913^{* *}$ & 0.298 & $0.866^{* *}$ & 0.265 & 0.191 & - & 0.179 & $0.830^{* *}$ & 0.587 & 0.707 * & 0.644 & 0.495 & -0.332 \\
\hline $\mathrm{SH}$ & 0.604 & 0.387 & 0.314 & 0.599 & -0.477 & 0.479 & - & 0.203 & 0.595 & 0.522 & 0.649 & 0.247 & -0.072 \\
\hline RL-upper & $0.998^{* *}$ & 0.356 & $0.833^{* *}$ & 0.554 & -0.046 & $0.893^{* *}$ & 0.633 & $0.956^{* *}$ & - & $0.912^{* *}$ & $0.983^{* *}$ & $0.845^{* *}$ & -0.286 \\
\hline RL-lower & 0.596 & 0.450 & 0.850 ** & -0.274 & 0.668 * & $0.756^{*}$ & 0.011 & 0.457 & 0.538 & - & $0.945^{* *}$ & $0.834^{* *}$ & -0.575 \\
\hline RL-fine & $0.998^{* *}$ & 0.336 & $0.844^{* *}$ & 0.528 & -0.014 & $0.917^{* *}$ & 0.616 & $0.948^{* *}$ & $0.997 * *$ & 0.581 & - & 0.779 * & -0.380 \\
\hline RL-coarse & $0.953^{* *}$ & 0.576 & $0.925^{* *}$ & 0.349 & 0.152 & $0.845^{* *}$ & 0.509 & $0.902 * *$ & $0.944^{* *}$ & 0.647 & $0.935^{* *}$ & - & -0.338 \\
\hline $\begin{array}{c}\text { RLR- } \\
\text { upper/lower }\end{array}$ & -0.493 & -0.253 & -0.761 * & 0.365 & -0.770 * & -0.690 * & 0.186 & -0.314 & -0.438 & $-0.903^{* *}$ & -0.484 & -0.513 & - \\
\hline
\end{tabular}




\subsubsection{Correlations in Root and Growth Parameters between Experiments}

Correlations were observed for the same traits in the semi-hydroponic system and the rhizobox system (38 DAS), with strong correlations at the 0.01 significance level for total root length, shoot mass, and root length (upper), and at the 0.05 significance level for hypocotyl length, shoot height, and root length (coarse) (Table 7a). However, there were no significant correlations for root diameter, root mass, specific root length, root-shoot mass ratio, root length (lower), root length (fine), or root length ratio (upper/lower), suggesting phenotypic plasticity in these traits at the seedling stage (Table 7a).

Table 7. Correlation of some important traits (ten root traits and three shoot traits) three soybean genotypes (\#054,\#055, and \#071) between the semi-hydroponic system (39 days after sowing, DAS) and the data from rhizoboxes assessed (a) 38 DAS, (b) 81 DAS, and (c) 160 DAS. At 160 DAS, only root mass (RM), root-shoot mass ratio (RSM), and shoot mass (SM), were measured.

\begin{tabular}{cccc}
\hline Traits & (a) 38 DAS & (b) 81 DAS & (c) 160 DAS \\
\hline RM & 0.591 & 0.665 & $0.901^{* *}$ \\
RSM & -0.648 & 0.187 & $0.884^{* *}$ \\
HL & $0.690^{*}$ & $0.670^{*}$ & $0.672^{*}$ \\
SH & $0.732^{*}$ & $0.801^{* *}$ & $0.776^{*}$ \\
SM & $0.887^{* *}$ & 0.511 & $0.900^{* *}$ \\
RL & $0.854^{* *}$ & $0.886^{* *}$ & - \\
RD & 0.004 & 0.310 & - \\
SRL & -0.397 & -0.563 & - \\
RL-upper & $0.831^{* *}$ & $0.851^{* *}$ & - \\
RL-lower & 0.299 & $0.866^{* *}$ & - \\
RL-fine & 0.179 & 0.202 & - \\
RL-coarse & $0.733^{*}$ & 0.664 & - \\
RLR-upper /lower & -0.196 & 0.195 &
\end{tabular}

Data collected in rhizoboxes (81 DAS) were correlated with data for the same traits collected from the semi-hydroponic system, with strong correlations at the 0.01 significance level for root length, shoot height, and root lengths (upper/lower), and at the 0.05 level for hypocotyl length (Table $7 \mathrm{~b}$ ). However, there were no significant correlations for rooting depth, root mass, specific root length, shoot mass, root lengths (coarse), root lengths (fine), or root length ratio (upper/lower), suggesting phenotypic plasticity in these traits at the reproductive stage (Table $7 \mathrm{~b}$ ).

Data collected in rhizoboxes (160 DAS) were correlated with data for the same traits collected from the semi-hydroponic system, with strong correlations at the 0.01 significance level for root mass, root-shoot mass ratio, and shoot mass, and at the 0.05 significance level for hypocotyl length and shoot height (Table 7c).

\section{Discussion}

\subsection{Variation among Root Architecture Traits}

Studying root phenomics is increasingly becoming a crop-breeding strategy [21,40,41]. In the present study, among the measured root traits, the maximal root depth, total root length, root mass, root length (coarse), and root length (fine) significantly differed among the tested genotypes (Table 1), indicating the importance of these root traits in root system function. Studies have shown that these root traits are most important for water and nutrient acquisition [15,42-44]. Soybean selection and breeding programs mainly focus on aboveground traits and yield, with the impact on root traits often ignored [27,41]. Genotypes \#54 (NG6255), \#71 (Xudou 16), and \#79 (NJP038) ranked in the small-rootsystem genotypes for total root length and root mass (Table S2, Figure 2). Genotypes \#030 (Graham), \#055 (Aijiaozao), and \#151 (NJP530) ranked in the largest-root-system genotypes in terms of total root length and root mass (Table S2, Figure 2). The vigorous root system of these soybean genotypes enhances the acquisition of deep soil nutrients 
and water $[3,45]$. Studies have confirmed that modern soybean cultivars have larger root systems than older cultivars [46,47] due to breeding for increased grain yield. However, both root system architecture commonly appeared in newly developed cultivars/lines in our study, indicating less selection of this type of root traits.

Total root length is an important trait affecting root mass [1,48]. In this study, genotypes with the largest root systems had seven times more total root length and 12 times more root mass than genotypes with the smallest root systems (Table 1). There was a positive trend between root length, root mass, and shoot mass in both the semi-hydroponic system and rhizoboxes (Tables 3 and 6). Total root length is an important factor affecting rooting depth [48]. Some studies have shown that the number of metaxylem elements in roots is correlated with drought tolerance in soybean [1,49]. Soybean genotypes with large root systems developed more metaxylem elements under drought stress, thus improving their resistance to stress [1].

As a leguminous species, soybean plants can form nodules to use nitrogen from the air on the cost of plant investment of carbon. Root system architecture could be altered during the nodulation [50], although some studies claimed no effect on the total root length of soybean following rhizobium inoculation [51]. The large phenotyping experiment was carried out under a semi-hydroponic environment, which was not suitable for the inoculation of rhizobium. The rhizoboxes experiment would have included rhizobium inoculation. However, inoculation was excluded to create non-inoculation conditions as in the semi-hydroponic system so that the root morphological traits of the selected three genotypes could be validated to confirm consistent genotype ranking in some important root traits (1) under both different growth conditions, (2) at early growth stages in both experiments, and (3) at different growth stages in the same soil environments. To avoid complexity involving inoculation treatments, adequate nitrogen was supplied to both experiments. The effects of rhizobium inoculation on soybean root configuration will be considered in our follow-up experiments through screening suitable rhizobium species and strains. Soybeans can form a symbiotic combination with rhizobium in a soil environment, which may be beneficial to improve nitrogen efficiency.

In this study, significant differences occurred between the soybean genotypes for the root lengths of coarse roots and fine roots. The genotype with the largest root system had seven times more root length (fine) and nine times more root length (coarse) than the smallest root system (Table 1). There were positive correlations between total root length, root length (coarse), and root length (fine) in both the semi-hydroponic system and rhizoboxes (Tables 3 and 6), indicating that soybean genotypes with larger root systems had more coarse and fine roots than genotypes with smaller root systems. Fine roots constitute most of the root surface area and root length in cacao (Theobroma cacao L.) and played a leading role in water and nutrient absorption [44]. Some studies have shown that coarse roots are related to waterlogging tolerance in soybean. Soybean genotypes with more root length of the coarse roots tolerated waterlogging better than genotypes with fewer coarse roots [52]. Therefore, genotypes with larger root systems could be selected as candidate parents.

\subsection{Genotype Selection Based on Root Trait Implications for Soybean Breeding}

This study measured 18 traits including 14 root-related traits and four shoot traits (13 global traits and five local traits). A large variation in these traits was identified among the 171 soybean genotypes. Nine traits had $C V \geq 0.3$, five of which were local traits (Table 1). Significant variation occurred in the local root traits of the tested soybean genotypes, especially for root length (lower) and root length (fine), which may be useful for breeding programs. Strong correlations between local traits and some global traits were identified in the Pearson's correlation matrix ( $p \leq 0.01$; Figure 4, Table 3$)$. Evidence of strong correlations between plant dry mass (shoot and root mass) and several local traits, including root length (upper) and root length (coarse), demonstrate that local traits are linked to plant growth strategies [53-55]. Studies have shown that crops with strong 
stress tolerance tend to have luxuriant root systems and high respiration rates in fine roots, which most likely reflects the metabolic activities related to nutrient absorption and assimilation $[43,56,57]$.

Among the 171 genotypes, 92 genotypes had 40 to 50 days to anthesis with $35 \%$ being the large root system and $40 \%$ being the small root system (Table S1). Among the 68 largeroot-system soybean genotypes, the days to maturity of $57 \%$ soybean genotypes was more than 100 days. We found that when genotypes had similar anthesis days, large-rooted genotypes had longer maturity days than other genotypes and absorbed more nutrients to meet the nutritional needs of the aboveground part during the mature period. This phenomenon may be controlled by some genes and needs further study.

Genotypes with a similar root system size (in terms of total root length and root mass) may distribute roots differently in the soil profile, as measured by root lengths (coarse/fine) and root lengths (upper/lower), mirror traits for total root length (Figures 3-5). Several recent studies in soybean and maize demonstrated that genotypes with luxuriant lateral roots had better root growth deeper in the profile, phosphorus uptake, and yield in infertile soil than those with fewer lateral roots $[43,58]$. For example, under phosphorus limited conditions, large root system genotypes generally had high phosphorus utilization efficiency, and small root system genotypes had low phosphorus utilization efficiency (unpublished data). Differences in salt tolerance among soybean genotypes of different root system sizes reflect a potential gene regulation mechanism and remain to be further explored.

Through the PCA and AHC, some genotypes with extreme traits (outliers) were screened (Figures 5, 6 and S2). Genotypes \#054 (NG6255), \#071 (Xudou 16), and \#079 (NJP038) had small root systems, genotypes \#161 (Tongdou 2006) and \#165 (Huaidou 10) had medium-sized root systems, and genotypes \#030 (Graham), \#055 (Aijiaozao) and \#153 (NJP553) had large root systems. Some studies showed the special advantages of the individual genotype tested here. The large root system genotype \#001 (Kefeng 1 Hao) is resistant to aluminum toxicity, and its seeds are resistant to storage [23,30]. Genotype \#014 (Sidou 520) is an early-maturing summer soybean with strong lodging resistance [59]. Genotype \#042 (Xudou 13) is high yielding and has strong drought resistance and high protein content [60]. The medium root system genotype \#165 (Huaidou 10) is high yielding [61]. The seeds of small root system genotypes \#092 (NJP133) and \#112 (Vance) are resistant to storage [23]. These differences between genotypes and root system size provide a reference for the selection of candidate parents.

\subsection{Validation of Root Characters in Soil}

Using the established semi-hydroponic phenotyping system [31], this study elucidated phenotypic variability in numerous root morphological traits among 171 genotypes of soybean from different geographical sources, which are likely related to the ability of different genotypes to respond to the environment to optimize resource acquisition [19]. Attempts have been made to incorporate the digital root images acquired in the semi-hydroponic system, automated high-throughput computing, and collaboration platforms, such as optical character recognition (OCR) [62] to analyze crop root phenomics, particularly root length (fine).

Three genotypes (\#054, \#055, and \#071) with putative differences in root system size were selected in a follow-up validation experiment using rhizoboxes filled with river sand soil. The large root system genotype, \#055 (Aijiaozao), is a direct parent of Chinese soybean cultivars [63], and it is also an old variety with good adaptation in Hubei province and the southern Huaihe River region [64]. The small root system genotype \#071 (Xudou 16) is a medium-maturing summer soybean cultivar with high and stable yield in the northern Huaihe River region [65]. The genotype \#054 (NG6255) is a high-yield and good lodging resistance line introduced from USA. The correlation analysis of the semi-hydroponic system and the rhizobox system (38 DAS) showed significant positive correlations between total root length, root length (upper) $(p \leq 0.01)$, and root length (coarse) $(p \leq 0.05)$ (Table 7a), indicating that the total root length at the soybean seedling stage mainly comprises root 
length (upper) and root length (coarse). The correlation analysis of the semi-hydroponic and the rhizobox systems (81 DAS) showed significant positive correlations between total root length and root lengths (upper/lower) (all $p \leq 0.01$; Table $7 \mathrm{~b}$ ), indicating that the total root length at the soybean reproductive stage mainly comprised root lengths (upper/lower). The correlation analysis showed significant positive correlations between root mass, rootshoot mass ratio, and shoot mass at soybean maturity between the semi-hydroponic and the rhizobox systems (160 DAS) (all $p \leq 0.01$; Table $7 \mathrm{c}$ ), indicating that these traits were intrinsic. Significant positive correlations between hypocotyl length and shoot height between the semi-hydroponic and the rhizobox systems at various growth stages (all $p \leq 0.05$; Table 7) confirmed that these shoot traits in later growth stages in soil can be predicted from the early growth in the semi-hydroponic system. However, several root traits including root diameter and root length ratio (upper/lower) (Table 7) were not significantly correlated under the two experimental conditions, which may indicate the plasticity of these traits in response to growth environments [32].

The experiment confirmed that phenotypic variation in the root system size at the seedling stage using the semi-hydroponic system in this phenotyping study was reproducible across the whole soybean growing period in the validation experiment using rhizoboxes. During the whole growing period, root growth positively correlated with the genotypic sequencing of some important root traits, indicating that the semi-hydroponic phenotypic system provides simple and reliable growing conditions for studying root phenotypes. A series of early studies on wild narrow-leafed lupin roots also revealed the susceptibility of the semi-hydroponic phenotypic system through repeated experiments in different environments (including field environments) $[32,33,66]$. Some studies have investigated the phenotypic correlation of roots in controlled and soil environments. For example, large root system genotypes \#001 (Kefeng 1 Hao), \#006 (Nannong 86-4), and \#014 (Sidou 520) had drought tolerance, \#030 (Graham) and \#042 (Xudou 13) had medium drought tolerance, and \#049 (t821058), \#051 (NT821060), \#055 (Aijiaozao), and \#067 (Suxian 21) had drought susceptibility [40]. In another study, small root system genotypes \#002 (Nannong 88-31) and \#079 (NJP038) had high drought tolerance, \#108 (Jilin 31) had drought tolerance, \#040 (Tongdou 7) and \#112 (Vance) had medium drought tolerance, \#052 (Zhechun 3 Hao), \#054 (NG6255), and \#071 (Xudou 16) had drought susceptibility [64].

However, there are limitations in converting phenotypic data from the seedling stage obtained from semi-hydroponic systems to soybean breeding programs. Roots may have specific responses in different growth environments, and phenotypic plasticity is important for searching for soil resources [18]. Therefore, the phenotypic system needs to produce a reliable ranking of root characteristics, and the selection of growth medium needs to be considered carefully. The development of modern root imaging technology and root simulation modeling can be integrated into the phenotypic platform.

\section{Materials and Methods}

Two glasshouse experiments were conducted in a temperature-controlled glasshouse at Northwest A\&F University, Yangling $\left(34^{\circ} 16^{\prime} \mathrm{N}, 108^{\circ} 4^{\prime \prime}\right.$ E) in 2018 and 2019, respectively. The first experiment using a semi-hydroponic phenotyping system [31] characterized root trait variability among 171 soybean (Glycine max L. Merr.) genotypes. The second experiment validated root properties of three genotypes selected from the semi-hydroponic system, using $1.5 \mathrm{~m}$ deep rhizoboxes filled with soil.

\subsection{Soybean Genotypes}

The semi-hydroponic experiment used 171 soybean genotypes (including 68 genotypes from the northern Huaihe River region, 75 genotypes from the southern Huaihe River region, and 28 parental lines, which had been previously tested in the field in the Yangtze and Huaihe River regions in eastern China [64]) (Table S1). Three genotypes, \#054, $\# 055$, and \#071, with contrasting root system size were selected for the validation study using soil-filled rhizoboxes. Seeds were provided by the National Center for Soybean 
Improvement, National Key Laboratory for Corp Genetics and Germplasm Enhancement, Soybean Research Institute, and Nanjing Agricultural University in Nanjing, China.

\subsection{Experimental Design, Layout, and Maintenance}

\subsubsection{The Semi-Hydroponic Phenotyping System}

A semi-hydroponic phenotyping system (Figure 1a) [31] was used to characterize root trait variability in 171 soybean genotypes. Each system comprises of one $240 \mathrm{~L}$ wheelie bin, 20 growth units made of a transparent acrylic panel $(250 \times 500 \mathrm{~mm}, 4 \mathrm{~mm}$ thick $)$ wrapped by black calico cloth, pump, and irrigation system, and supporting frames [31,67]. The black cotton cloth in the plant growth unit retains moisture through the automatic pumping system. Each bin was filled with $30 \mathrm{~L}$ nutrient solution containing $(\mu \mathrm{M}): \mathrm{K}(1220)$, $\mathrm{P}(50), \mathrm{S}$ (1802), $\mathrm{Ca}(600), \mathrm{Mg}(200), \mathrm{Cu}(0.2), \mathrm{Zn}(0.75), \mathrm{Mn}$ (0.75), B (5), Co (0.2), Na (0.06), Mo (0.03), Fe (40), and N (1000).

Soybean seeds were sown in two lots on two separate days to create a one-day difference in planting and subsequent harvest for ease of the process. Seeds were surfacesterilized in $10 \% \mathrm{H}_{2} \mathrm{O}_{2}$ for $10 \mathrm{~min}$ and sown in pots filled with water-washed river sand. After six days, geminated seedlings with $2-3 \mathrm{~cm}$ long roots were carefully washed free of sands and transferred into the growth system. Two plants of two different genotypes were transplanted into each growth unit with 40 plants per bin system. Four plants of each genotype were planted in four replicate bins. Twenty-four bins were arranged in a randomized block design with six bins as one replicate. Buffer plants were used when required to ensure an equal number of plants assigned to each bin. The average daily temperature during the experimental period was approximately $25 / 15{ }^{\circ} \mathrm{C}$ (day/night). The water supply time was controlled by a timer. Constant water supply was given during the first three days after transplantation. Then, the water was supplied with $10 \mathrm{~min}$ on and 5 min off for the remainder of the experiment using a timer to control the pump/irrigation system. Each bin was randomly repositioned once a week. The nutrient solution was refreshed weekly.

\subsubsection{Soil-Filled Rhizoboxes}

A randomized block design comprising three soybean genotypes (\#054, \#055, and \#071) selected from the semi-hydroponic experiments was conducted with three harvests and three replicates. Each rhizobox served as a replicate for a total of 27 rhizoboxes $(25 \mathrm{~cm}$ long $\times 5 \mathrm{~cm}$ wide $\times 150 \mathrm{~cm}$ deep). Rhizoboxes were constructed from polyvinyl chloride (PVC) with one glass side that was covered with a black PVC sheet to block the light. The rhizoboxes were placed on steel stands at a $30^{\circ}$ angle. Each rhizobox was filled with $28.5 \mathrm{~kg}$ of air-dried distill water washed river sand $(<2 \mathrm{~mm})$ and irrigated with $5 \mathrm{~L}$ of nutrition solution as the same in the semi-hydroponic system. Nutrient solution was applied weekly. Four seeds were surface-sterilized and sown on 16 May 2019 in a row close to the glass wall of each rhizobox. Seedlings were thinned to two plants per rhizobox at the cotyledon stage. Plants were watered twice a day ( $300 \mathrm{~mL}$ each time) when the nutrition solution was not applied. Rhizoboxes were randomly repositioned once a week. The average daily temperature during the experimental period was approximately $30 / 20^{\circ} \mathrm{C}$ (day/night).

\subsection{Measurements and Assessments}

\subsubsection{The Semi-Hydroponic Phenotyping System}

Plants were assessed 39 days after sowing (DAS). At harvest, the values of maximum physical height of plant shoots, leaf number, and taproot length per plant were measured manually. Shoot height was measured with a ruler from the cotyledon node to the peak of the main stem. The growth panels were taken out of the bin and placed on a flat bench with a black background. The cloth was removed from the growth panel to expose the root systems for photographing using a camera (Sony LICE-7, SONY CORP, Tokyo, Japan) installed above the workbench. Shoots and roots were separated after photographing. Maximal root width (the maximal horizontal width of a root system), root angle (maximal 
growth angle between two outermost lateral roots) (Figure 1c), and hypocotyl root length were measured using ImageJ (1.51j8, Wayne Rasband, National Institutes of Health, USA). Shoot dry weight (i.e., shoot mass) was determined after drying in an air-forced oven at 75 ${ }^{\circ} \mathrm{C}$ for $72 \mathrm{~h}$. Root subsamples were collected by cutting the root system into $10 \mathrm{~cm}$ sections from the base, which were stored in a $4{ }^{\circ} \mathrm{C}$ refrigerator until scanning for morphological and architectural measurements. After scanning, root subsamples from the same plant were collected as one root sample and dried in an oven to obtain root dry mass.

\subsubsection{Soil-Filled Rhizoboxes}

Plants were harvested 38 days after sowing (DAS), 81 DAS, and 160 DAS. The number of visible roots via the glass wall was recorded every seven days after the VC stage (unifoliolate leaves completely expanded, 9 DAS) until harvest. For each weekly measurement, the black PVC cover was removed, and the glass wall was covered with transparent plastic film (A4 paper size) to trace the visible new roots using a waterproof permanent black marker pen. After removing the transparent film from the glass wall, all visible new roots were also traced onto the glass wall before covering the glass wall with the black PVC cover. The root growth data were obtained by scanning the film with a desktop scanner (Epson Perfection V800, Long Beach, CA, USA) on each mapping day.

At harvests, the maximum physical height of plant shoots and hypocotyl length was measured manually. The black PVC cover and glass wall were removed from the rhizobox to expose the visible root systems for photographing using a camera installed above the workbench with the method similar to the semi-hydroponic system. After photographing, the shoots and roots were separated at the soil surface. Shoot dry mass was determined after drying in an air-forced oven. Roots subsamples were collected by cutting the root system into $10 \mathrm{~cm}$ sections from the base. The subsamples were washed on a $1.4 \mathrm{~mm}$ sieve with water. The roots were stored in a $4{ }^{\circ} \mathrm{C}$ refrigerator until scanning for morphological and architectural measurements. The method of measuring root dry mass is the same as the semi-hydroponic experiments.

\subsection{Root Scanning and Root Image Analysis}

Root section samples from both experiments and root tracing films from soil-filled rhizoboxes (except for root samples harvested at 160 DAS) were scanned in grayscale at 300 dpi using a desktop scanner (Epson Perfection V800, Long Beach, CA, USA). The root images for each $10 \mathrm{~cm}$ segment were analyzed using WinRhizo Pro (v2009, Regent Instruments, Montreal, QC, Canada). Imaging was analyzed using the debris removal filter of discounting objects $<1 \mathrm{~cm}^{2}$ with a length-width ratio $<8$ in the image. Root morphology data, such as total root length, average root diameter for each root section, and root length for different diameter classes were generated in the WinRhizo program. Root length diameters $<0.5 \mathrm{~mm}$ were categorized as fine roots, and $\geq 0.5 \mathrm{~mm}$ were categorized as coarse roots. The following root traits were calculated from the measured data:

Specific root length (SRL) = total root length/root dry mass;

Root tissue density (RTD) = total root dry mass / root volume;

Root-shoot mass ratio (RSM) = total root dry mass / shoot dry mass;

Root length ratio (upper/lower) = root length in top $20 \mathrm{~cm}$ section/root length below $20 \mathrm{~cm}$ soil depth.

The 18 root traits were divided into two general categories (semi-hydroponic system): 13 global traits (whole plant level) and five local traits (Table 2). Global traits refer to the whole root system and whole shoots, and local root traits refer to roots in different depths and diameter classes.

\subsection{Data Treatment and Analysis}

One-way ANOVA was conducted using SPSS Statistics 22 (IBM Corporation, Somers, NY, USA) for significant differences among the tested genotypes for each trait. Figures were plotted using SigmaPlot 12.5 (Systat, USA) and Origin 2021 (OriginLab, Northamp- 
ton, MA, USA). Correlations were considered statistically significant at $p \leq 0.05\left(^{*}\right)$ or $\left.p \leq 0.01{ }^{* *}\right)$. Traits with coefficients of variation $(\mathrm{CV}) \geq 0.3$ were selected for principal component analysis (PCA) to identify determinants of root architecture variability across genotypes [68]. Hierarchical cluster analysis was used to determine the variance among the selected root traits and homogeneous groups among the genotypes using the Euclidean distance method.

\section{Conclusions}

The quality root data and consistent ranking of genotypes in root traits demonstrated the reliability of the semi-hydroponic system in phenotyping root trait variability among a large set of soybean genotypes. Substantial variation in root-related traits across 171 soybean genotypes was identified and validated in selected three genotypes with contrasting root system properties. Genotypes with interesting root system architecture traits, including total root length, root mass, root lengths in diameter coarse, root lengths in diameter fine and trait-trait relationships, could be used for crossing with widely adapted cultivars in soybean breeding programs after further observations of their performance under field conditions. With the availability of the whole genome sequencing data of the soybean resources used in this study, we will conduct genome-wide association analysis study (GWAS) to identify loci and genes controlling specific root morphological traits. The eventual aims of these studies are to select and breed soybean cultivars with suitable root traits for enhanced adaptation to adverse environments and improved nutrient and water use efficiency.

Supplementary Materials: The following are available online at https:/ / www.mdpi.com/article/10 .3390 / plants10122781/s1, Table S1: List of the 171 genotypes of soybean (Glycine max L. Merr.) used in the phenotyping study using a semi-hydroponic system with three selected genotypes used in the validation experiment using rhizoboxes in this study. Information about adaptive regions, days to anthesis, and days to maturity (from seed emergence; VE-R1 stage), root system size, and drought tolerance is provided, Table S2: Soybean genotypes ranked in the top 15 (large values, indicated by ) or bottom 15 (small values, indicated by $\star$ ) among 171 genotypes from the phenotyping experiment for total root length (RL), with some also ranked in the top/bottom 15 for other traits. Figure S1: Root mass (RM; a), total root length (RL; b), root length in diameter fine (RL-fine; c), and root length in diameter coarse (RL-coarse; $d$ ) for genotypes in three source categories NHHR (68 genotypes), SHHR (75 genotypes), and PL (28 genotypes) used in the phenotyping experiment. NHHR, northern Huaihe River region; SHHR, southern Huaihe River region; PL, parental lines. The 171 genotypes were grown in a semi-hydroponic phenotyping platform 39 days after sowing. Significant differences are shown for the three source categories $(p \leq 0.05)$. The whiskers, box, and dot are determined by the 5th and 95th percentiles, 25th and 75th percentiles, and the 1st and 99th percentiles, respectively. The line and dashed inside the box marks are the median and mean, respectively, Figure S2: Principal component analysis of nine selected traits with CVs $\geq 0.3$ across 171 soybean genotypes grown in a semi-hydroponic phenotyping platform 39 days after sowing. The position of each trait is shown for PC1 vs. PC2 representing $78.6 \%$ of the total variability. The genotypes with extreme traits (outliers) are indicated by genotype number. NHHR, northern Huaihe River region; SHHR, southern Huaihe River region; PL, parental lines.

Author Contributions: Conceptualization, Y.C., T.Z., H.T.N. and K.H.M.S.; Data curation, S.L., T.A., S.Z. and X.D.; Formal analysis, S.L., N.B. and Y.C.; Funding acquisition, Y.C. and H.-M.L.; Investigation, S.L. and T.A.; Methodology, T.Z., B.X., S.Z., X.D., H.-M.L., K.H.M.S. and Y.C.; Project administration, B.X. and Y.C.; Resources, N.B., T.Z., H.-M.L. and H.T.N.; Software, N.B.; Supervision, Y.C.; Validation, S.L.; Visualization, S.L. and T.A.; Writing-original draft, S.L. and Y.C.; WritingReview and editing, Y.C., T.Z., B.X., S.Z., X.D., H.-M.L., H.T.N. and K.H.M.S. All authors have read and agreed to the published version of the manuscript.

Funding: This research was funded by the National Natural Science Foundation of China (42077055), and Hong Kong Research Grants Council Area of Excellence Scheme (AoE/M-403/16).

Informed Consent Statement: Not applicable. 
Data Availability Statement: Relevant data generated or analyzed during this study are included in this article and its supplementary information files. Other data are available upon request to the corresponding author.

Acknowledgments: We are grateful for Yan Fang, Sheng Qiao, Hao Wang, Qingxia Miao, Di Huang, Baoxing Liu, Liyan Liang from Northwest A\&F University, and Wenliang Yan from Nanjing Agricultural University, China for their assistance in this study.

Conflicts of Interest: The authors declare no conflict of interest.

\section{Abbreviations}

AHC: Agglomerative hierarchical clustering; GLM: General Linear Model; p: Probability; PCA: Principal component analysis.

\section{References}

1. Valliyodan, B.; Ye, H.; Song, L.; Murphy, M.; Shannon, J.G.; Nguyen, H.T. Genetic diversity and genomic strategies for improving drought and waterlogging tolerance in soybeans. J. Exp. Bot. 2017, 68, 1835-1849. [CrossRef]

2. Liu, X.Q.; He, J.B.; Wang, Y.F.; Xing, G.N.; Li, Y.; Yang, S.P.; Zhao, T.J.; Gai, J.Y. Geographic differentiation and phylogeographic relationships among world soybean populations. Crop J. 2020, 8, 260-272. [CrossRef]

3. Li, S.Y.; Wang, W.B.; Cao, Y.Q.; Wang, C.L.; Yan, C.J.; Dong, L.J.; Wu, L.S.; Xie, F.T.; Song, S.H. How root traits would be affected by soybean yield improvement? An examination of historical cultivars grafted with record-yield cultivar scion. Plant Soil 2019, 439, 19-30. [CrossRef]

4. Rosolem, C.A.; Neto, L.O.; Costa, V.E.; Grassmann, C.D. Ruzigrass root persistence and soybean root growth. Plant Soil 2019, 442, 333-341. [CrossRef]

5. Schmidt, J.; Messmer, M.; Wilbois, K.P. Beneficial microorganisms for soybean (Glycine max (L.) Merr), with a focus on low root-zone temperatures. Plant Soil 2015, 397, 411-445. [CrossRef]

6. Chen, W.; Yao, Q.M.; Patil, G.B.; Agarwal, G.; Deshmukh, R.K.; Lin, L.; Wang, B.; Wang, Y.Q.; Prince, S.J.; Song, L.; et al. Identification and comparative analysis of differential gene expression in soybean leaf tissue under drought and flooding stress revealed by RNA-Seq. Front. Plant Sci. 2016, 7, 1044. [CrossRef]

7. Wu, C.J.; Zeng, A.L.; Chen, P.Y.; Hummer, W.; Mokua, J.; Shannon, J.G.; Nguyen, H.T. Evaluation and development of floodtolerant soybean cultivars. Plant Breed. 2017, 136, 913-923. [CrossRef]

8. Seminario, A.; Song, L.; Zulet, A.; Nguyen, H.T.; Gonzalez, E.M.; Larrainzar, E. Drought stress causes a reduction in the biosynthesis of ascorbic acid in soybean plants. Front. Plant Sci. 2017, 8, 1042. [CrossRef]

9. Jin, T.; Sun, Y.Y.; Shan, Z.; He, J.B.; Wang, N.; Gai, J.Y.; Li, Y. Natural variation in the promoter of GsERD15B affects salt tolerance in soybean. Plant Biotechnol. J. 2020, 19, 1155-1169. [CrossRef]

10. Ge, Y.; Li, Y.; Zhu, Y.M.; Bai, X.; Lv, D.K.; Guo, D.J.; Ji, W.; Cai, H. Global transcriptome profiling of wild soybean (Glycine soja) roots under $\mathrm{NaHCO}_{3}$ treatment. BMC Plant Biol. 2010, 10, 153. [CrossRef]

11. Foyer, C.H.; Nguyen, H.T.; Lam, H.M. Legumes-The art and science of environmentally sustainable agriculture. Plant Cell Environ. 2019, 42, 1-5. [CrossRef]

12. Rehman, H.M.; Cheung, W.L.; Wong, K.S.; Xie, M.; Luk, C.Y.; Wong, F.L.; Li, M.W.; Tsai, S.N.; To, W.T.; Chan, L.Y.; et al. Highthroughput mass spectrometric analysis of the whole proteome and secretome from Sinorhizobium fredii strains CCBAU25509 and CCBAU45436. Front. Microbiol. 2019, 10, 2569. [CrossRef]

13. Zhao, H.Y.; Yang, A.H.; Kong, L.J.; Xie, F.T.; Wang, H.Y.; Ao, X. Proteome characterization of two contrasting soybean genotypes in response to different phosphorus treatments. AoB Plants 2021, 13, plab019. [CrossRef]

14. Zhu, J.M.; Ingram, P.A.; Benfey, P.N.; Elich, T. From lab to field, new approaches to phenotyping root system architecture. Curr. Opin. Plant Biol. 2011, 14, 310-317. [CrossRef]

15. Sun, X.C.; Ren, W.; Wang, P.; Chen, F.J.; Yuan, L.X.; Pan, Q.C.; Mi, G.H. Evaluation of maize root growth and genome-wide association studies of root traits in response to low nitrogen supply at seedling emergence. Crop J. 2021, 9, 794-804. [CrossRef]

16. Mi, G.H.; Chen, F.J.; Yuan, L.X.; Zhang, F. Ideotype root system architecture for maize to achieve high yield and resource use efficiency in intensive cropping systems. Adv. Agron. 2016, 139, 73-97.

17. van der Bom, F.J.T.; Williams, A.; Bell, M.J. Root architecture for improved resource capture: Trade-offs in complex environments. J. Exp. Bot. 2020, 71, 5752-5763. [CrossRef]

18. Lynch, J.P.; Strock, C.F.; Schneider, H.M.; Sidhu, J.S.; Ajmera, I.; Galindo-Castañeda, T.; Klein, S.P.; Hanlon, M.T. Root anatomy and soil resource capture. Plant Soil 2021, 466, 21-63. [CrossRef]

19. Yang, W.N.; Feng, H.; Zhang, X.H.; Zhang, J.; Doonan, J.H.; Batchelor, W.D.; Xiong, L.Z.; Yan, J.B. Crop phenomics and highthroughput phenotyping: Past decades, current challenges, and future perspectives. Mol. Plant 2020, 13, 187-214. [CrossRef] [PubMed]

20. Song, P.; Wang, J.L.; Guo, X.Y.; Yang, W.N.; Zhao, C.J. High-throughput phenotyping: Breaking through the bottleneck in future crop breeding. Crop J. 2021, 9, 633-645. [CrossRef] 
21. Prince, S.J.; Valliyodan, B.; Ye, H.; Yang, M.; Tai, S.S.; Hu, W.S.; Murphy, M.; Durnell, L.A.; Song, L.; Joshi, T.; et al. Understanding genetic control of root system architecture in soybean: Insights into the genetic basis of lateral root number. Plant Cell Environ. 2019, 42, 212-229. [CrossRef] [PubMed]

22. Hina, A.; Cao, Y.C.; Song, S.Y.; Li, S.G.; Sharmin, R.A.; Elattar, M.A.; Bhat, J.A.; Zhao, T.J. High-resolution mapping in two RIL populations refines major "QTL Hotspot" regions for seed size and shape in soybean (Glycine max L.). Int. J. Mol. Sci. 2020, 21, 1040. [CrossRef] [PubMed]

23. Zhang, X.; Xu, M.G.; Hina, A.; Kong, J.J.; Gai, J.Y.; He, X.H.; Zhao, T.J. Seed storability of summer-planting soybeans under natural and artificial aging conditions. Legum. Res. 2019, 42, 250-259. [CrossRef]

24. Chang, F.G.; Guo, C.Y.; Sun, F.L.; Zhang, J.S.; Wang, Z.L.; Kong, J.J.; He, Q.Y.; Sharmin, R.A.; Zhao, T.J. Genome-wide association studies for dynamic plant height and number of nodes on the main stem in summer sowing soybeans. Front. Plant Sci. 2018, 9, 1184. [CrossRef]

25. Cao, Y.C.; Li, S.G.; He, X.H.; Chang, F.G.; Kong, J.J.; Gai, J.Y.; Zhao, T.J. Mapping QTLs for plant height and flowering time in a Chinese summer planting soybean RIL population. Euphytica 2017, 213, 39. [CrossRef]

26. Pan, L.Y.; He, J.B.; Zhao, T.J.; Xing, G.N.; Wang, Y.F.; Yu, D.Y.; Chen, S.Y.; Gai, J.Y. Efficient QTL detection of flowering date in a soybean RIL population using the novel restricted two-stage multi-locus GWAS procedure. Theor. Appl. Genet. 2018, 131, 2581-2599. [CrossRef]

27. Cao, Y.C.; Li, S.G.; Chen, G.L.; Wang, Y.F.; Bhat, J.A.; Karikari, B.; Kong, J.J.; Gai, J.Y.; Zhao, T.J. Deciphering the genetic architecture of plant height in soybean using two RIL populations sharing a common M8206 parent. Plants 2019, 8, 373. [CrossRef]

28. Chang, F.G.; Lv, W.H.; Lv, P.Y.; Xiao, Y.T.; Yan, W.L.; Chen, S.; Zheng, L.Y.; Xie, P.; Wang, L.; Karikari, B.; et al. Exploring genetic architecture for pod-related traits in soybean using image-based phenotyping. Mol. Breed. 2021, 41, 28-49. [CrossRef]

29. Khan, M.A.; Tong, F.; Wang, W.B.; He, J.B.; Zhao, T.J.; Gai, J.Y. Analysis of QTL-allele system conferring drought tolerance at seedling stage in a nested association mapping population of soybean (Glycine max (L.) Merr.) using a novel GWAS procedure. Planta 2018, 248, 947-962. [CrossRef]

30. Korir, P.C.; Zhang, J.; Wu, K.; Zhao, T.; Gai, J. Association mapping combined with linkage analysis for aluminum tolerance among soybean cultivars released in Yellow and Changjiang River Valleys in China. Theor. Appl. Genet. 2013, 126, 1659-1675. [CrossRef] [PubMed]

31. Chen, Y.L.; Dunbabin, V.M.; Diggle, A.J.; Siddique, K.H.M.; Rengel, Z. Development of a novel semi-hydroponic phenotyping system for studying root architecture. Funct. Plant Biol. 2011, 38, 355-363. [CrossRef] [PubMed]

32. Chen, Y.L.; Dunbabin, V.M.; Postma, J.A.; Diggle, A.J.; Palta, J.A.; Lynch, J.P.; Siddique, K.H.M.; Rengel, Z. Phenotypic variability and modelling of root structure of wild Lupinus angustifolius genotypes. Plant Soil 2011, 348, 345-364. [CrossRef]

33. Chen, Y.L.; Dunbabin, V.M.; Diggle, A.J.; Siddique, K.H.M.; Rengel, Z. Assessing variability in root traits of wild Lupinus angustifolius germplasm: Basis for modelling root system structure. Plant Soil 2012, 354, 141-155. [CrossRef]

34. Chen, Y.L.; Shan, F.C.; Nelson, M.N.; Siddique, K.H.M.; Rengel, Z. Root trait diversity, molecular marker diversity, and trait-marker associations in a core collection of Lupinus angustifolius. J. Exp. Bot. 2016, 67, 3683-3697. [CrossRef]

35. Chen, Y.; Ghanem, M.E.; Siddique, K.H.M. Characterising root trait variability in chickpea (Cicer arietinum L.) germplasm. J. Exp. Bot. 2017, 68, 1987-1999.

36. Qiao, S.; Fang, Y.; Wu, A.; Xu, B.; Zhang, S.; Deng, X.; Djalovic, I.; Siddique, K.H.M.; Chen, Y. Dissecting root trait variability in maize genotypes using the semi-hydroponic phenotyping platform. Plant Soil 2019, 439, 75-90. [CrossRef]

37. Chen, Y.; Palta, J.; Prasad, P.V.V.; Siddique, K.H.M. Phenotypic variability in bread wheat root systems at the early vegetative stage. BMC Plant Biol. 2020, 20, 185. [CrossRef] [PubMed]

38. Halder, T.; Liu, H.; Chen, Y.; Yan, G.J.; Siddique, K.H.M. Identification of candidate genes for root traits using genotype-phenotype association analysis of near-isogenic lines in hexaploid wheat (Triticum aestivum L.). Int. J. Mol. Sci. 2021, 22, 3579. [CrossRef]

39. Wang, J.D.; Chen, Y.; Zhang, Y.E.; Zhang, Y.C.; Ai, Y.C.; Feng, Y.P.; Moody, D.; Diggle, A.; Damon, P.; Rengel, Z. Phenotyping and validation of root morphological traits in barley (Hordeum vulgare L.). Agron. J. 2021, 11, 1583. [CrossRef]

40. Kuijken, R.C.; van Eeuwijk, F.A.; Marcelis, L.F.; Bouwmeester, H.J. Root phenotyping: From component trait in the lab to breeding. J. Exp. Bot. 2015, 66, 5389-5401. [CrossRef]

41. Falk, K.G.; Jubery, T.Z.; O'Rourke, J.A.; Singh, A.; Sarkar, S.; Ganapathysubramanian, B.; Singh, A.K. Soybean root system architecture trait study through genotypic, phenotypic, and shape-based clusters. Plant Phenomics 2020, 2020, 1925495. [CrossRef]

42. Wen, Z.H.; Li, H.B.; Shen, Q.; Tang, X.M.; Xiong, C.Y.; Li, H.G.; Pang, J.Y.; Ryan, M.H.; Lambers, H.; Shen, J. Tradeoffs among root morphology, exudation and mycorrhizal symbioses for phosphorus-acquisition strategies of 16 crop species. New Phytol. 2019, 223, 882-895. [CrossRef]

43. Lynch, J.P. Root phenotypes for improved nutrient capture: An underexploited opportunity for global agriculture. New Phytol. 2019, 223, 548-564. [CrossRef] [PubMed]

44. Zobel, R.W.; Kinraide, T.B.; Baligar, V.C. Fine root diameters can change in response to changes in nutrient concentrations. Plant Soil 2007, 297, 243-254. [CrossRef]

45. Xiong, R.T.; Liu, S.; Considine, M.J.; Siddique, K.H.M.; Lam, H.M.; Chen, Y. Root system architecture, physiological and transcriptional traits of soybean (Glycine max L.) in response to water deficit: A review. Physiol. Plant 2021, 172, 405-418. [CrossRef] 
46. Yang, X.H.; Wu, Z.P.; Zhang, G.D. Evolution of root characters of soybean varieties developed in different years. Agric. Sci. China 2002, 1, 71-75.

47. Mitchell, R.L.; Russell, W.J. Root development and rooting patterns of soybean (Glycine max (L.) Merrill) evaluated under field conditions. Agron. J. 1971, 63, 313-316. [CrossRef]

48. Araki, H.; Morita, S.; Tatsumi, J.; Iijima, M. Physiol-morphological analysis on axile root growth in upland rice. Plant Prod. Sci. 2002, 5, 286-293. [CrossRef]

49. Rincon, C.A.; Raper, C.D.J.; Patterson, R.P. Genotypic differences in root anatomy affecting water movement through roots of soybean. Int. J. Plant Sci. 2003, 164, 543-551. [CrossRef]

50. Xavier, L.J.C.; Germida, J.J. Selective interactions between arbuscular mycorrhizal fungi and Rhizobium leguminosarum bv. viceae enhance pea yield and nutrition. Biol. Fertil. Soils 2003, 37, 261-267. [CrossRef]

51. Wang, X.; Pan, Q.; Chen, F.; Yan, X.; Liao, H. Effects of co-inoculation with arbuscular mycorrhizal fungi and rhizobia on soybean growth as related to root architecture and availability of N and P. Mycorrhiza 2011, 21, 173-181. [CrossRef]

52. Jitsuyama, Y. Morphological root responses of soybean to rhizosphere hypoxia reflect waterlogging tolerance. Can. J. Plant Sci. 2015, 95, 999-1005. [CrossRef]

53. Suriyagoda, L.D.B.; Lambers, H.; Renton, M.; Ryan, M.H. Growth, carboxylate exudates and nutrient dynamics in three herbaceous perennial plant species under low, moderate and high phosphorus supply. Plant Soil 2012, 358, 105-117. [CrossRef]

54. Fan, J.W.; Du, Y.L.; Turner, N.C.; Wang, B.R.; Fang, Y.; Xi, Y.; Guo, X.R.; Li, F.M. Changes in root morphology and physiology to limited phosphorus and moisture in a locally-selected cultivar and an introduced cultivar of Medicago sativa L. growing in alkaline soil. Plant Soil 2015, 392, 215-226. [CrossRef]

55. Wu, A.J.; Fang, Y.; Liu, S.; Wang, H.; Xu, B.C.; Zhang, S.Q.; Deng, X.P.; Palta, J.A.; Siddique, K.H.M.; Chen, Y.L. Root morphology and rhizosheath acid phosphatase activity in legume and graminoid species respond differently to low phosphorus supply. Rhizosphere 2021, 19, 100391. [CrossRef]

56. Tjoelker, M.G.; Craine, J.M.; Wedin, D.; Reich, P.B.; Tilman, D. Linking leaf and root trait syndromes among 39 grassland and savannah species. New Phytol. 2005, 167, 493-508. [CrossRef] [PubMed]

57. Roumet, C.; Urcelay, C.; Diaz, S. Suites of root traits differ between annual and perennial species growing in the field. New Phytol. 2006, 170, 357-368. [CrossRef]

58. Vandamme, E.; Renkens, M.; Pypers, P.; Smolders, E.; Vanlauwe, B.; Merckx, R. Root hairs explain P uptake efficiency of soybean genotypes grown in a P-deficient Ferralsol. Plant Soil 2013, 369, 269-282. [CrossRef]

59. Zhang, X.M. Growth characteristics and cultivation techniques of a new soybean variety Sidou 520. Seed Ind. Guide 2010, 3, 27-28. (In Chinese)

60. Zheng, L. Characteristics and high-yield cultivation techniques of Xudou 13. Xiandai Nongye Keji 2008, 19, 243-244. (In Chinese)

61. Zhou, C.Z.; He, L.G.; Lin, H.M. Characteristics and high-yielding cultivation techniques of a new soybean variety Huaidou 10. Bull. Agric. Sci. Technol. 2008, 8, 139-140, (In Chinese with English abstract).

62. Falk, K.G.; Jubery, T.Z.; Mirnezami, S.V.; Parmley, K.A.; Sarkar, S.; Singh, A.; Ganapathysubramanian, B.; Singh, A.K. Computer vision and machine learning enabled soybean root phenotyping pipeline. Plant Methods 2020, 16, 5. [CrossRef] [PubMed]

63. Xiong, D.J.; Zhao, T.J.; Gai, J.Y. Parental analysis of soybean cultivars released in China. Sci. Agric. Sin. 2008, 41, 2589-2598, (In Chinese with English abstract).

64. Wang, Y.D.; Xu, M.G.; Zhang, Y.J.; Weng, Y.Y.; Li, X.Y.; Kong, J.J.; Zhao, T.J.; He, X.H. Identification of drought-tolerance of soybean germplasms from Yangtze and Huaihe River Valleys at seedling stage. Soybean Sci. 2017, 36, 669-678, (In Chinese with English abstract).

65. Wang, X.; Wang, Z.B.; Xu, Z.J. Breeding and cultivation techniques of a new soybean variety Xudou 16. Soybean Sci. Technol. 2011, 6, 64-65, (In Chinese with English abstract).

66. Chen, Y.L.; Palta, J.; Clements, J.; Buirchell, B.; Siddique, K.H.M.; Rengel, Z. Root architecture alteration of narrow-leafed lupin and wheat in response to soil compaction. Field Crops Res. 2014, 165, 61-70. [CrossRef]

67. Chen, Y.; Zhou, T.; Siddique, K.H.M. Method for characterization of root traits in chickpea germplasm for legume genomics and breeding. In Legume Genomics; Jain, M., Garg, R., Eds.; Humana: New York, NY, USA, 2020; Volume 2017, pp. $269-275$.

68. Jolliffe, I.T.; Cadima, J. Principal component analysis: A review and recent developments. Philos. Trans. R. Soc. A 2016, 374, 20150202. [CrossRef] 